Review Article

\title{
Prevalence of Splanchnic Vein Thrombosis in Pancreatitis: A Systematic Review and Meta-Analysis of Observational Studies
}

\author{
Wenda Xu, ${ }^{1}$ Xingshun Qi, ${ }^{2}$ Jiang Chen, ${ }^{2}$ Chunping Su, ${ }^{3}$ and Xiaozhong Guo ${ }^{2}$ \\ ${ }^{1}$ The 251st Hospital of PLA, Zhangjiakou 075000, China \\ ${ }^{2}$ Department of Gastroenterology, Shenyang General Hospital of PLA, Shenyang 110840, China \\ ${ }^{3}$ Library of Fourth Military Medical University, Xian 710032, China
}

Correspondence should be addressed to Xiaozhong Guo; guoxiaozhong1958@163.com

Received 18 October 2014; Accepted 24 November 2014

Academic Editor: Valerio De Stefano

Copyright (C) 2015 Wenda Xu et al. This is an open access article distributed under the Creative Commons Attribution License, which permits unrestricted use, distribution, and reproduction in any medium, provided the original work is properly cited.

\begin{abstract}
Splanchnic vein thrombosis (SVT) may be negatively associated with the prognosis of pancreatitis. We performed a systematic review and meta-analysis of literatures to explore the prevalence of SVT in pancreatitis. All observational studies regarding the prevalence of SVT in pancreatitis were identified via PubMed and EMBASE databases. The prevalence of SVT was pooled in the total of patients with pancreatitis. And it was also pooled in the subgroup analyses according to the stage and causes of pancreatitis, location of SVT, and regions where the studies were performed. After the review of 714 studies, 44 studies fulfilled the inclusion criteria. Meta-analyses showed a pooled prevalence of SVT of $13.6 \%$ in pancreatitis. According to the stage of pancreatitis, the pooled prevalence of SVT was $16.6 \%$ and $11.6 \%$ in patients with acute and chronic pancreatitis, respectively. According to the causes of pancreatitis, the pooled prevalence of SVT was $12.2 \%$ and $14.6 \%$ in patients with hereditary and autoimmune pancreatitis. According to the location of SVT, the pooled prevalence of portal vein, splenic vein, and mesenteric vein thrombosis was $6.2 \%$, $11.2 \%$, and $2.7 \%$ in pancreatitis. The prevalence of SVT in pancreatitis was $16.9 \%, 11.5 \%$, and $8.5 \%$ in Europe, America, and Asia, respectively.
\end{abstract}

\section{Introduction}

Splanchnic vein thrombosis (SVT) is one such vascular complication of pancreatitis. SVT involves the portal vein (PV), splenic vein $(\mathrm{SplV})$, and mesenteric vein (MV) with the occurrence in combination or separately [1]. The consequence of pancreatitis-induced SVT may generate a localized form of portal hypertension and then splenoportal or gastroepiploic systems burden following localized venous hypertension and lead to gastric, oesophageal, or colonic varices. It may also cause the liver failure, bowel ischemia, and gastrointestinal bleeding [2]. Patients suffer from great pain and potentially lethal threaten. The limited literature cannot acquire an exact prevalence of SVT in pancreatitis. The aim of the present systematic review and meta-analysis is to obtain the prevalence of SVT in pancreatitis by resolving the following three questions. (1) What is the prevalence of SVT in pancreatitis, including PVT, SplVT, and MVT? (2) What is the prevalence of SVT in different types of pancreatitis?
(3) What is the prevalence of SVT in pancreatitis in different regions? This study is conducted according to the guidelines for the reporting of meta-analysis of observational studies, which were published by the Meta-analysis of Observational Studies in Epidemiology Group in 2000 [3].

\section{Methods}

As a systematic review and meta-analysis were planned, we reviewed standard guidelines to conduct meta-analysis studies according to a protocol determined before the study, including study objectives, prespecified eligibility criteria, and methods of statistical analysis.

\subsection{Eligibility Criteria}

(1) The participants of any age were diagnosed with pancreatitis, including acute pancreatitis (AP), chronic 


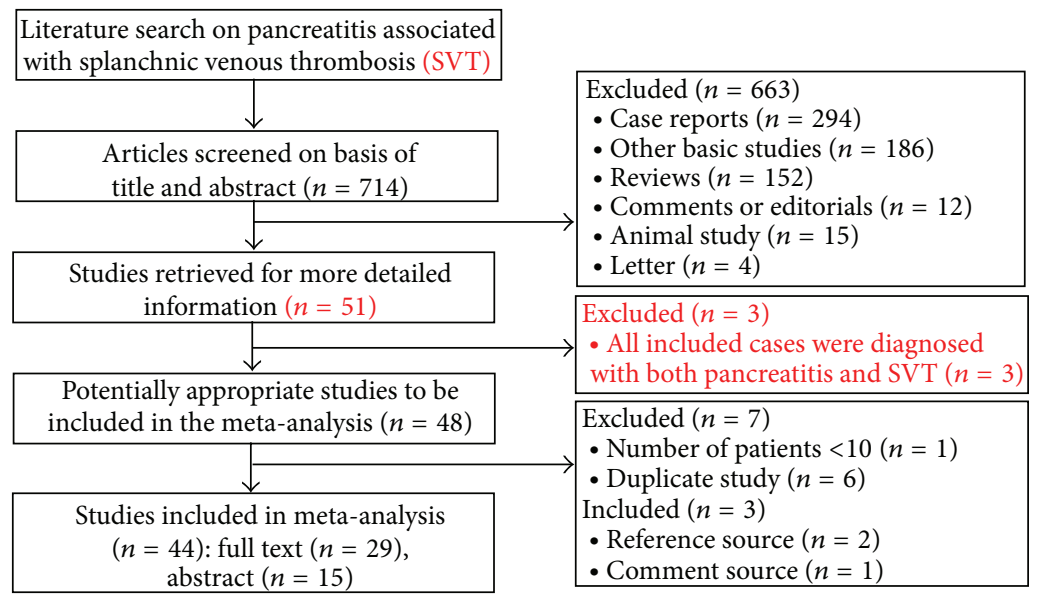

FIGURE 1: Flow diagram of study selection.

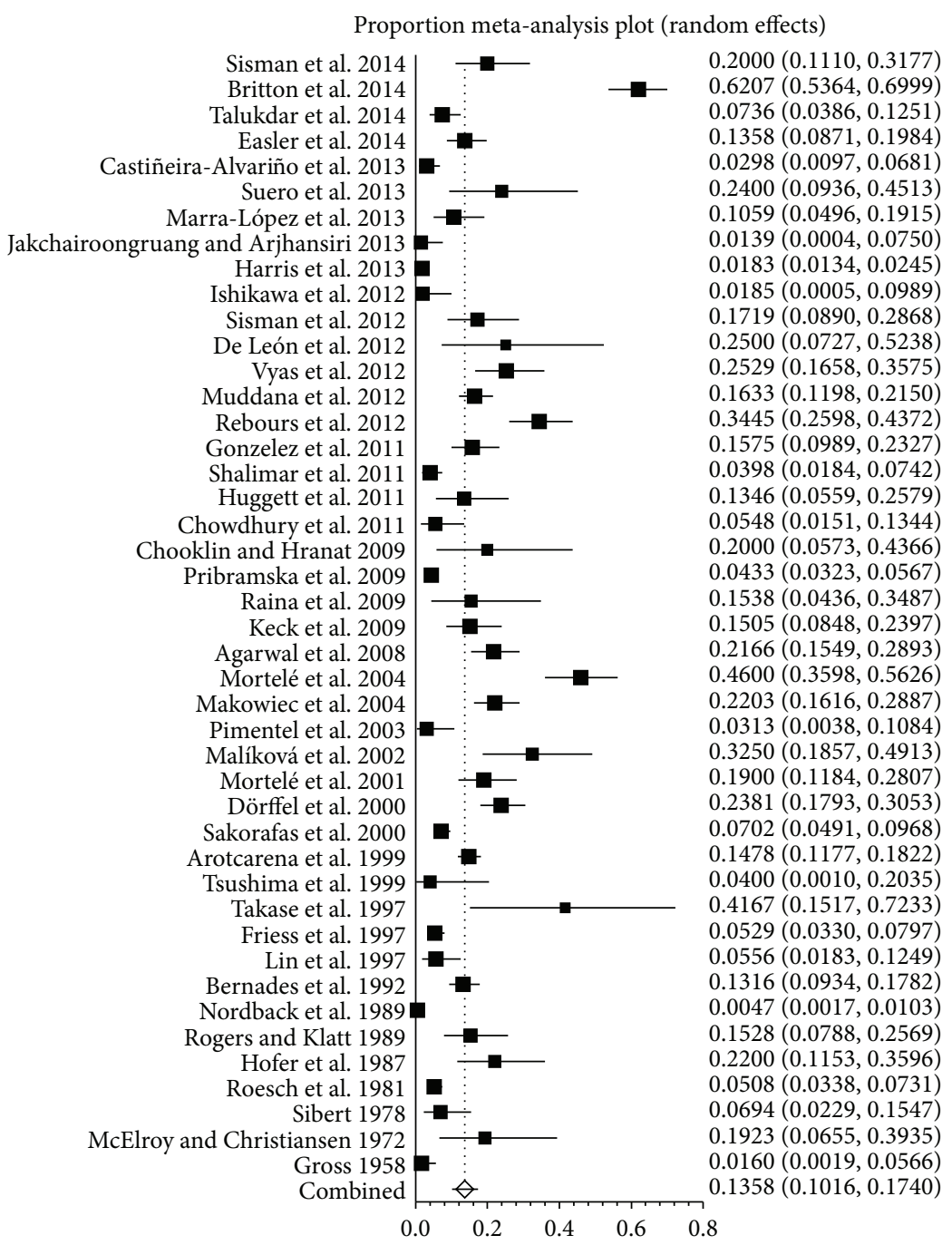

Proportion (95\% confidence interval)

FIGURE 2: Forest plots showing the prevalence of splanchnic vein thrombosis (SVT) in pancreatitis. 
Proportion meta-analysis plot (fixed effects)

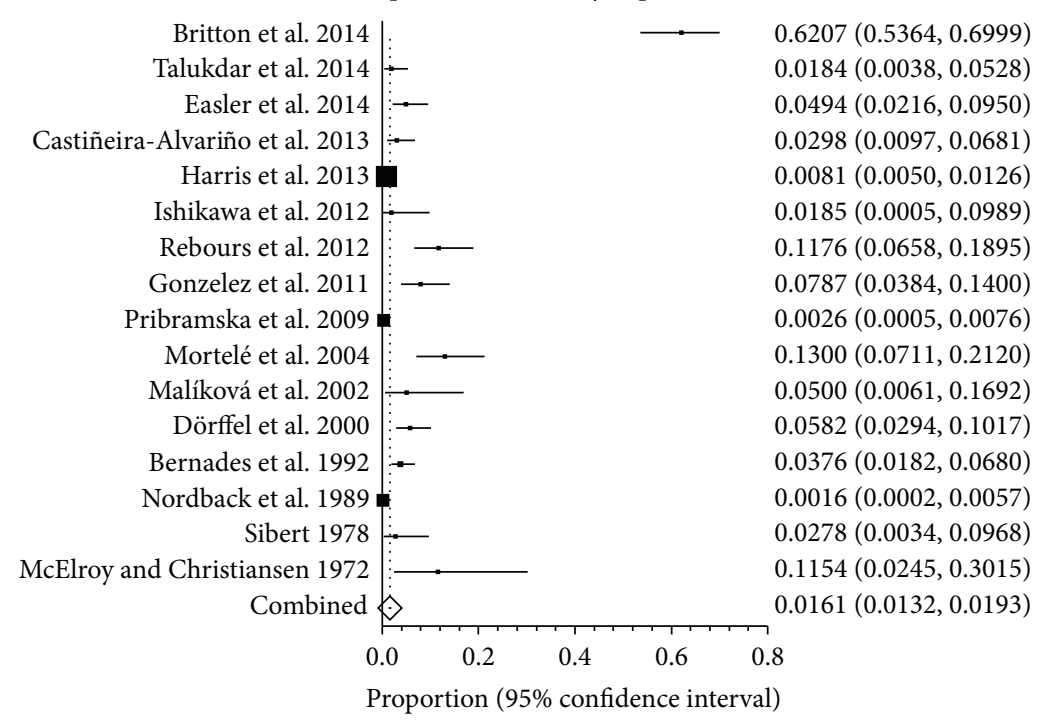

(a)

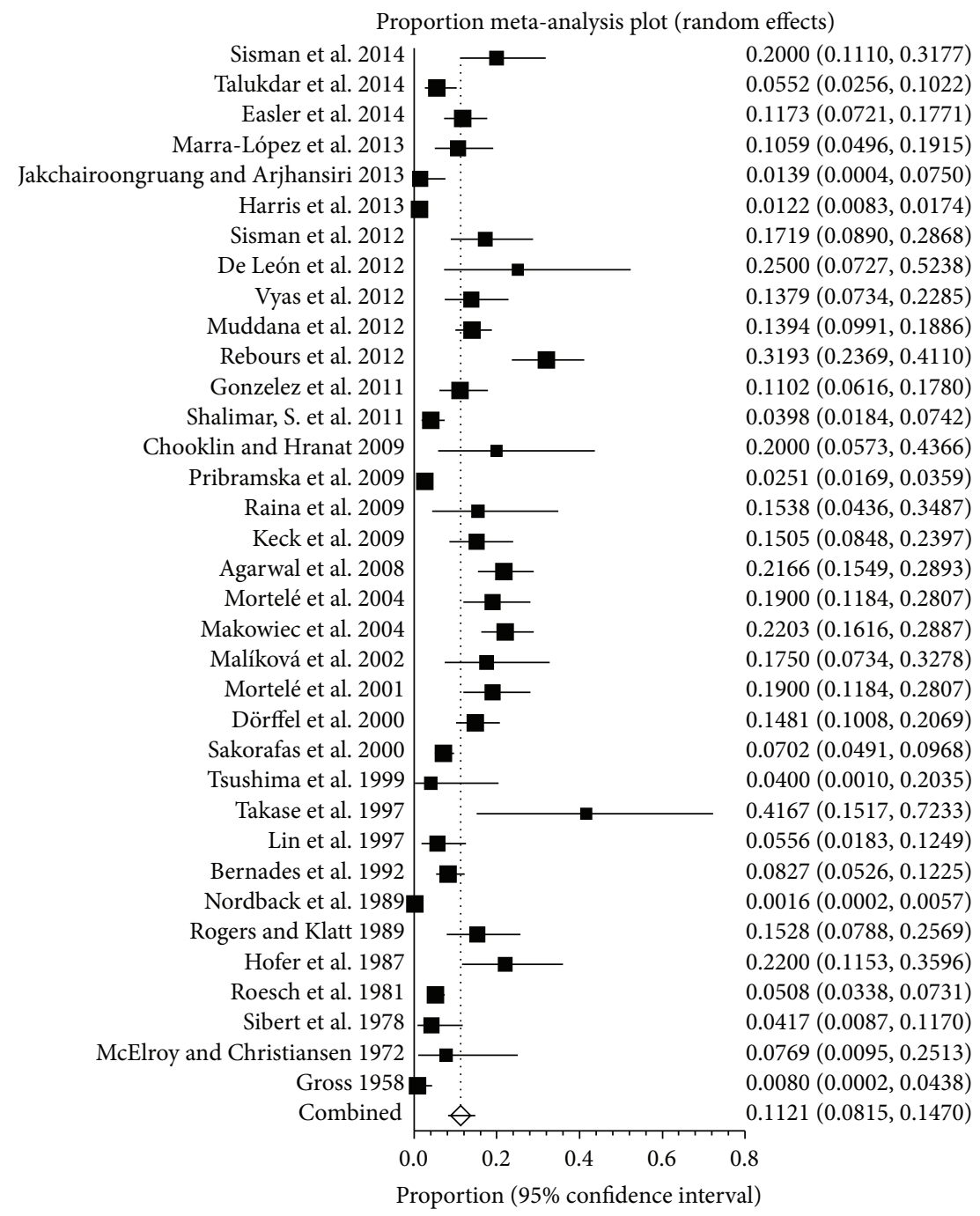

(b)

FIgure 3: Continued. 


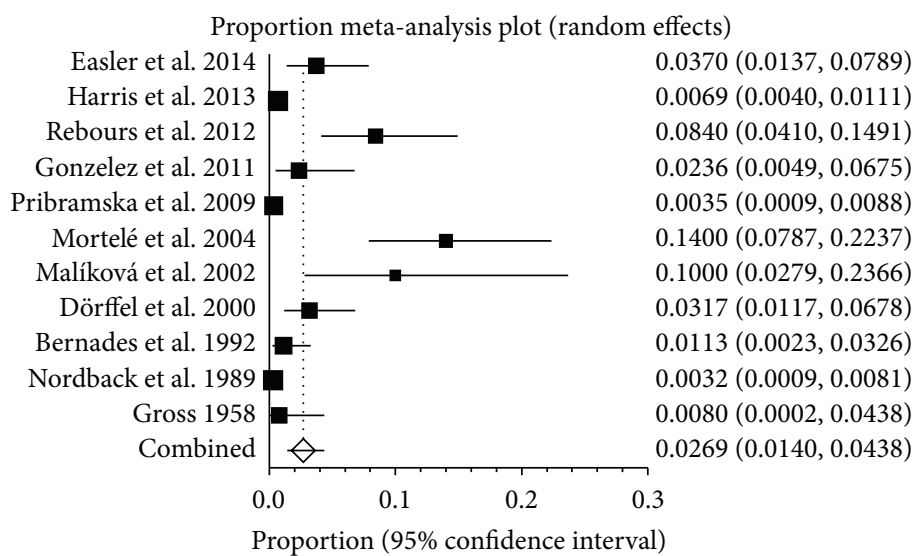

(c)

FIGURE 3: (a) Forest plots showing the prevalence of portal vein thrombosis (PVT) in pancreatitis. (b) Forest plots showing the prevalence of splenic vein thrombosis (SlpVT) in pancreatitis. (c) Forest plots showing the prevalence of mesenteric vein thrombosis (MVT) in pancreatitis.

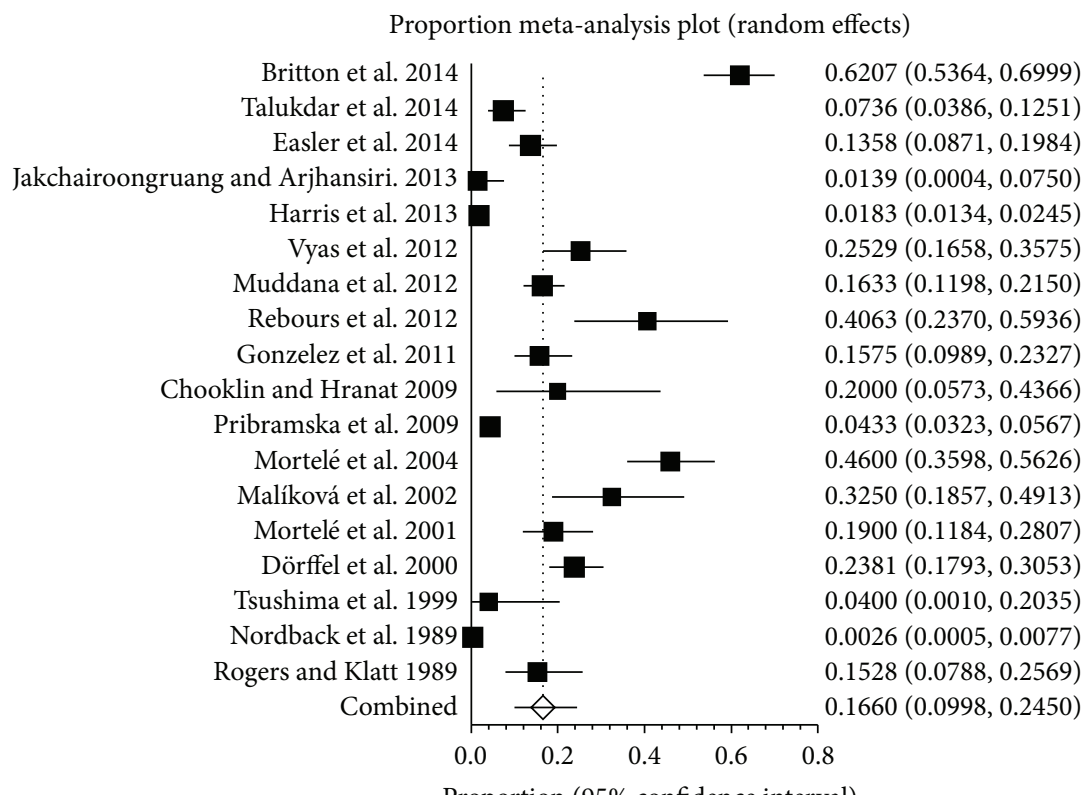

Proportion (95\% confidence interval)

(a)

Proportion meta-analysis plot (random effects)

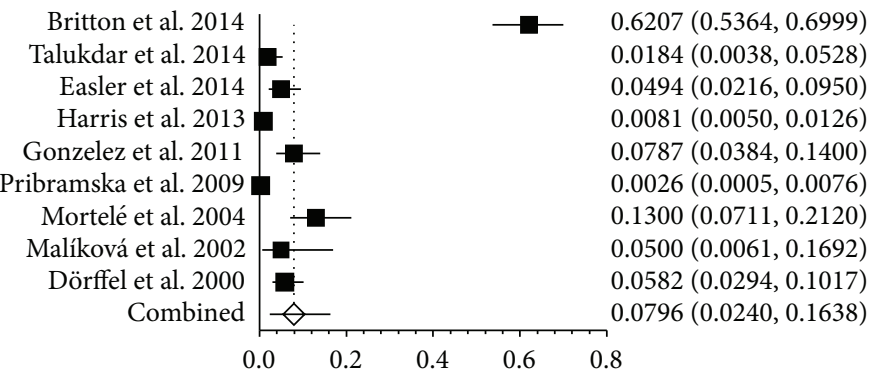

Proportion (95\% confidence interval)

(b)

FIGURE 4: Continued. 


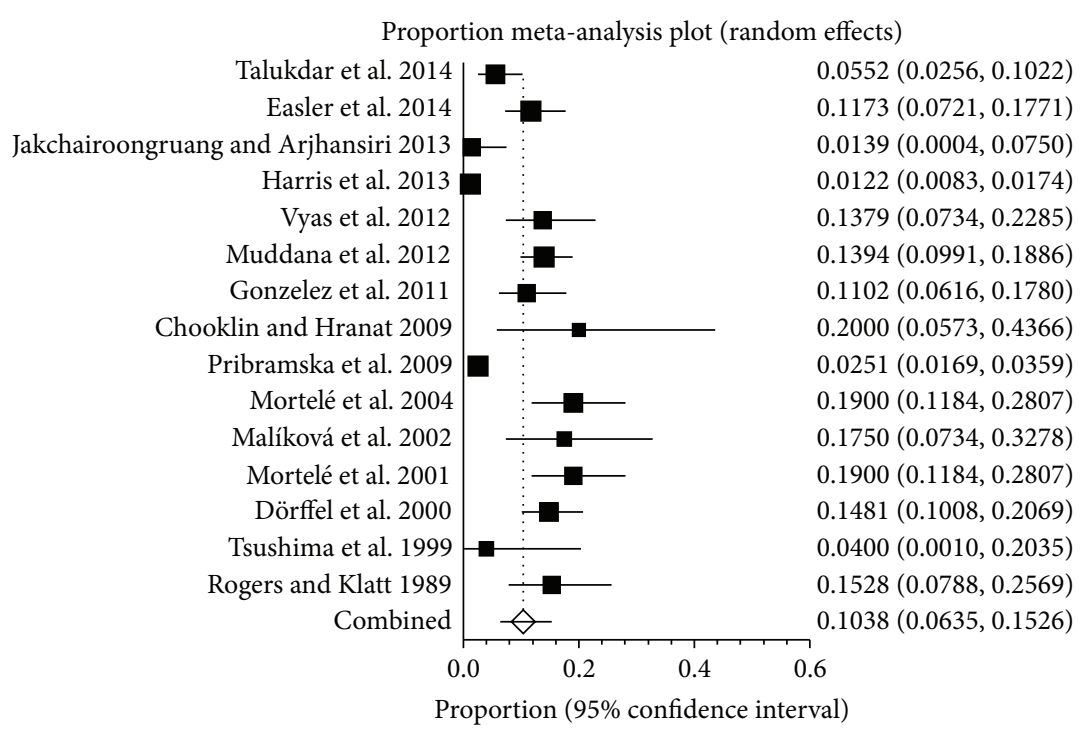

(c)

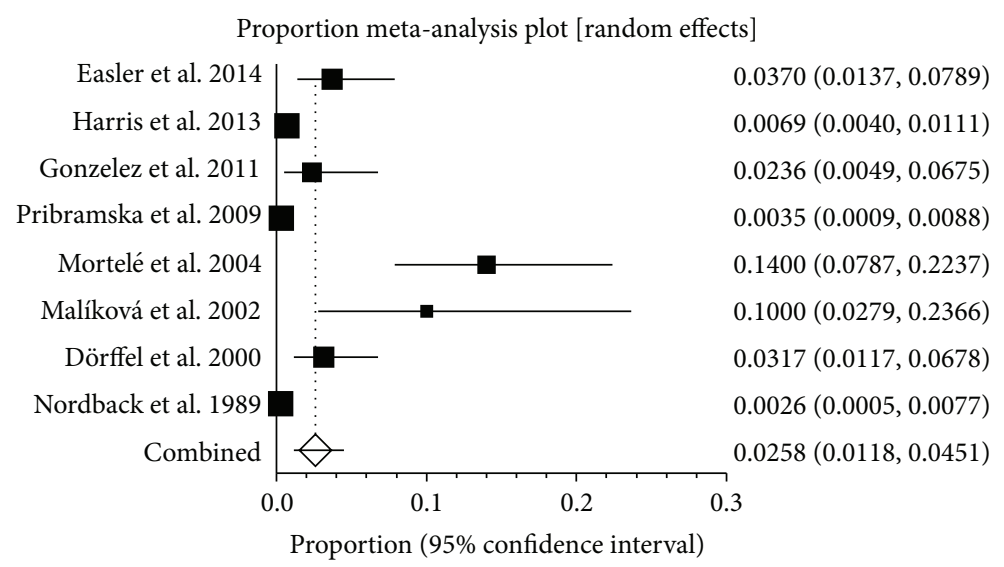

(d)

FIGURE 4: (a) Forest plots showing the prevalence of splanchnic vein thrombosis (SVT) in acute pancreatitis (AP). (b) Forest plots showing the prevalence of portal vein thrombosis (PVT) in acute pancreatitis (AP). (c) Forest plots showing the prevalence of splenic vein thrombosis (SlpVT) in acute pancreatitis (AP). (d) Forest plots showing the prevalence of mesenteric vein thrombosis (MVT) in acute pancreatitis (AP).

pancreatitis (CP), hereditary pancreatitis (HP), or autoimmune pancreatitis (AIP). The participants with underlying malignancy, cirrhosis, trauma, abdominal surgery unrelated to ongoing pancreatitis, pregnancy, intra-abdominal infections, primary myeloproliferative disorders, or other pancreatic diseases or pancreatitis and resultant SVT were not deliberately excluded.

(2) All cohort and case-control studies were eligible, regardless of the retrospective or prospective nature of the study; case reports were excluded.

(3) Reviews, comments, or letters on the relationship of pancreatitis and SVT were excluded.

(4) Animal studies were also excluded.

(5) There was no publication date or publication status restrictions.
(6) There were no language restrictions.

(7) The number of participants in any included study was beyond 10 .

2.2. Search Strategy. The MEDLINE and EMBASE databases were searched using a search strategy from their inception to July 2014. Search items combined keywords and medical subject heading terms (MeSH) were listed as follows: ("pancreatitis" (MeSH Terms) or "pancreatitis" (All Fields)) and (("portal vein" (MeSH Terms) or ("portal" (All Fields) and "vein" (All Fields)) or "portal vein" (All Fields)) and ("thrombosis" (MeSH Terms) or "thrombosis" (All Fields))) or (("splenic vein" (MeSH Terms) or ("splenic" (All Fields) and "vein" (All Fields)) or "splenic vein" (All Fields)) and ("thrombosis" (MeSH Terms) or "thrombosis" (All Fields))) or (("mesenteric veins" (MeSH Terms) or ("mesenteric" (All Fields) and "veins" (All Fields)) or "mesenteric veins" 
Proportion meta-analysis plot (random effects)

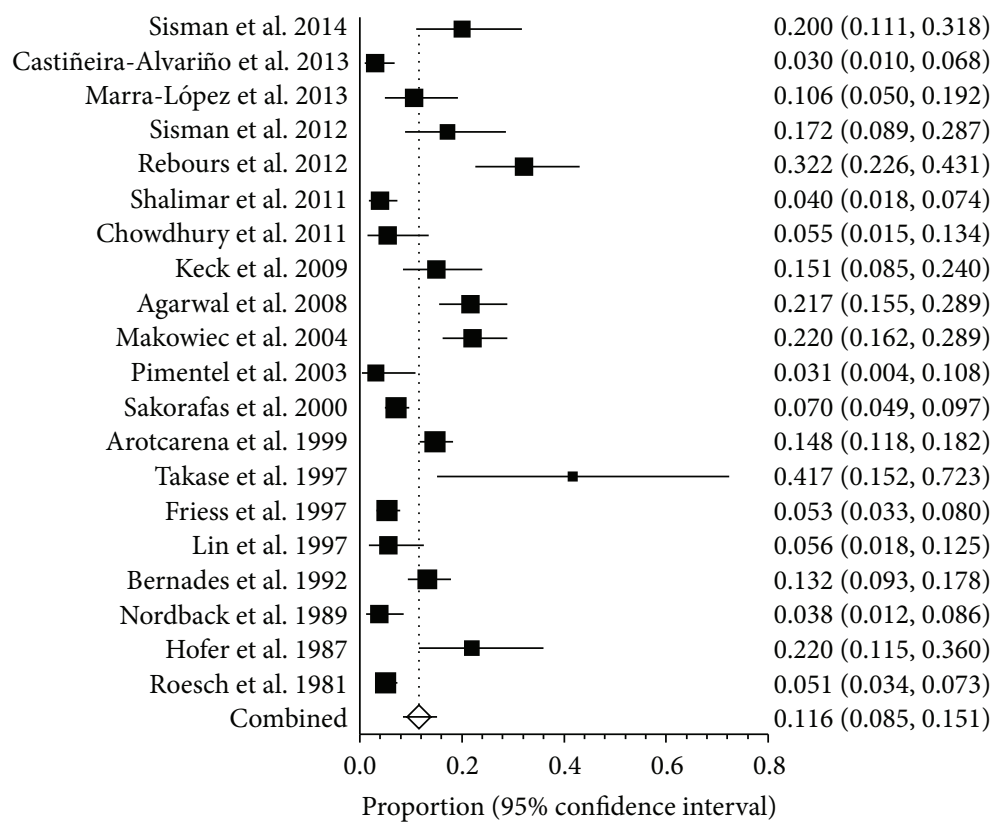

(a)

Proportion meta-analysis plot (random effects)

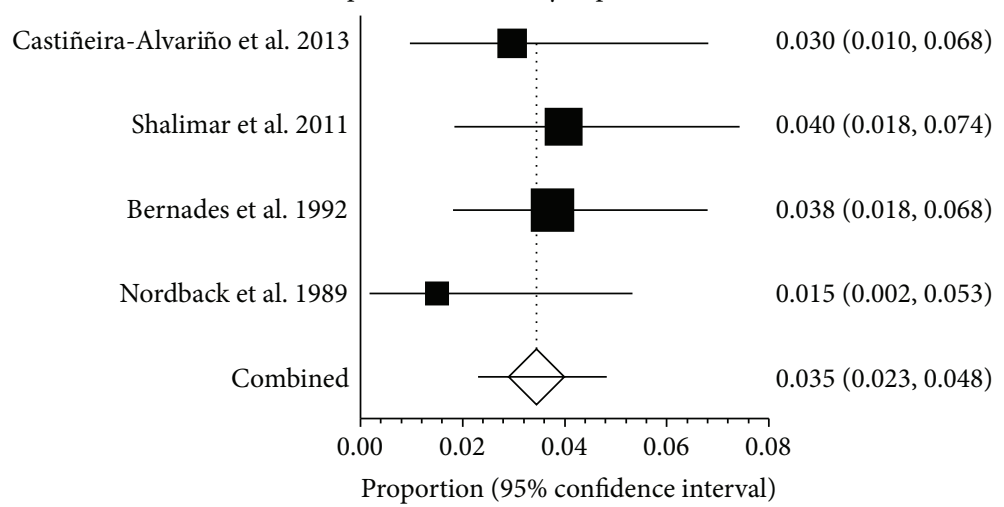

(b)

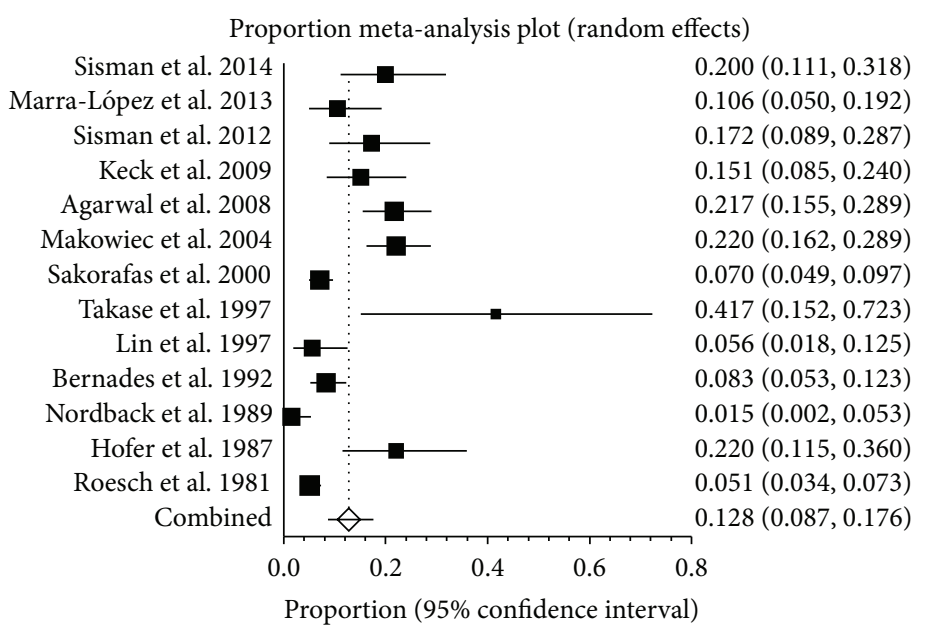

(c)

Figure 5: Continued. 


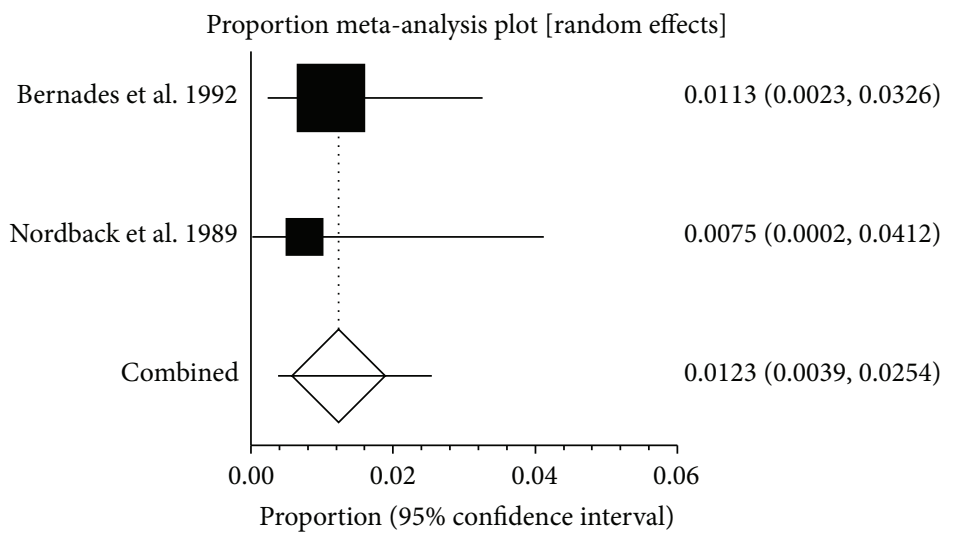

(d)

FIGURE 5: (a) Forest plots showing the prevalence of splanchnic vein thrombosis (SVT) in chronic pancreatitis (CP). (b) Forest plots showing the prevalence of portal vein thrombosis (PVT) in chronic pancreatitis (CP). (c) Forest plots showing the prevalence of splenic vein thrombosis (SlpVT) in chronic pancreatitis (CP). (d) Forest plots showing the prevalence of mesenteric vein thrombosis (MVT) in chronic pancreatitis $(\mathrm{CP})$.

(All Fields) or ("mesenteric" (All Fields) and "vein" (All Fields)) or "mesenteric vein" (All Fields)) and ("thrombosis" (MeSH Terms) or "thrombosis" (All Fields))). The last search was performed on July 29, 2014. The reference lists of the included articles were further hand-searched to identify any additional relevant studies. When the same data were found in more than one publication, only the studies with more complete data and more extensive interval of enrolment were included in the meta-analysis. Full-texts were found by three investigators (Wenda Xu, Xingshun Qi, and Chunping Su).

2.3. Data Extraction. Using a predefined protocol, two investigators (Wenda Xu and Xingshun Qi) independently reviewed the titles and abstracts of all references to identify studies for inclusion in the analysis. Dealing with disagreement between the two reviewers, a consensus was achieved through discussion among all of the reviewers. A schematic diagram depicting reference flow is shown through the systematic review process. Additionally, a data extraction sheet was generated that included authors, publication year, study design, country where the study was conducted, period of enrolment, inclusion and exclusion criteria, type of diseases (AP, CP, HP, or AIP), total sample size, demographic data (age and gender), number of patients with PVT, SplV, or MVT, and proportion of patients with PVT, SplV, or MVT, respectively.

2.4. Evaluation of Study Quality. Quality assessment of studies was carried out independently by two reviewers (Wenda $\mathrm{Xu}$ and Xingshun Qi). Discrepancies of interpretation and comprehension were resolved by consensus. The higher quality studies should fulfill the following predetermined criteria.

(1) Country where the study was conducted, interval of enrolment, inclusion and exclusion criteria, and participant characteristics (age, gender) were clearly recorded.
(2) Pancreatitis was diagnosed on the basis of history, clinical manifestations, elevated serum lipase and amylase, imaging detection by ultrasonography (US), endoscopic ultrasonography (EUS), computed tomography (CT), magnetic resonance imaging (MRI), or endoscopic retrograde cholangiopancreatography (ERCP), and/or typical histopathology.

2.5. Data Synthesis and Statistical Analysis. The proportion of pancreatitis patients with SVT in each study was combined to give a pooled prevalence of SVT for all studies. With this method, the pooled prevalence of PVT, SplV, and MVT was calculated. Furthermore, according to the type of pancreatitis and continents (Europe, America, and Asia), the pooled prevalence of SVT, PVT, SplV, and MVT was also created. The number and crude proportion of participants with SVT recorded by each study were used to pool the overall proportion, using the DerSimonian-Laird random-effects method. Between-study heterogeneity was assessed by using the $I^{2}$ index $\left(I^{2}>50 \%\right.$ was considered having substantial heterogeneity) and the Chi-squared test $(P<0.01$ was considered representing significant statistical heterogeneity) [4]. Individualized random effects meta-analyses were performed to estimate percentages and 95\% confidence intervals (CIs) for all endpoints queried. Analyses were conducted using StatsDirect statistical software version 2.7.8 (StatsDirect Ltd, Sale, Cheshire, UK).

\section{Results}

3.1. Description of the Included Studies. In the initial search strategy, a total of 947 studies were selected. Among them, 714 studies were retrieved by removing duplicate research. Two additional unique references were found through reference lists of an original article and a review, respectively $[5,6]$. One study as object of related comment was also identified [7]. Total of 44 studies were included in the meta-analysis 
Proportion meta-analysis plot [random effects]

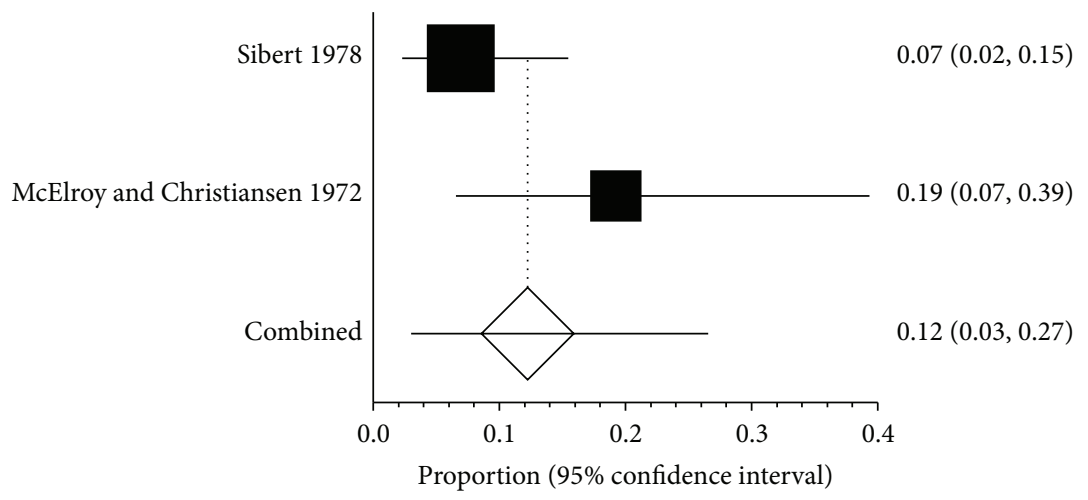

(a)

Proportion meta-analysis plot [random effects]

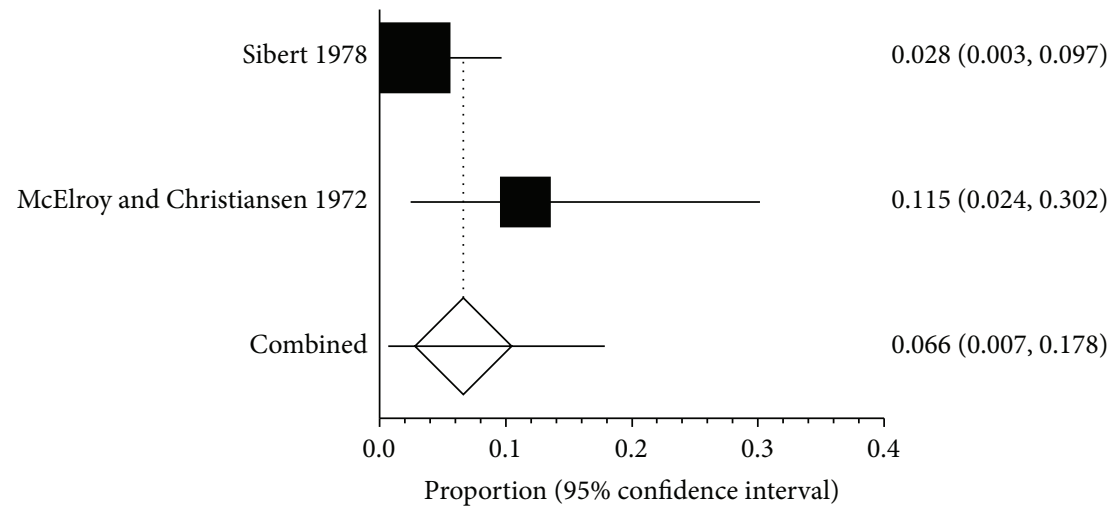

(b)

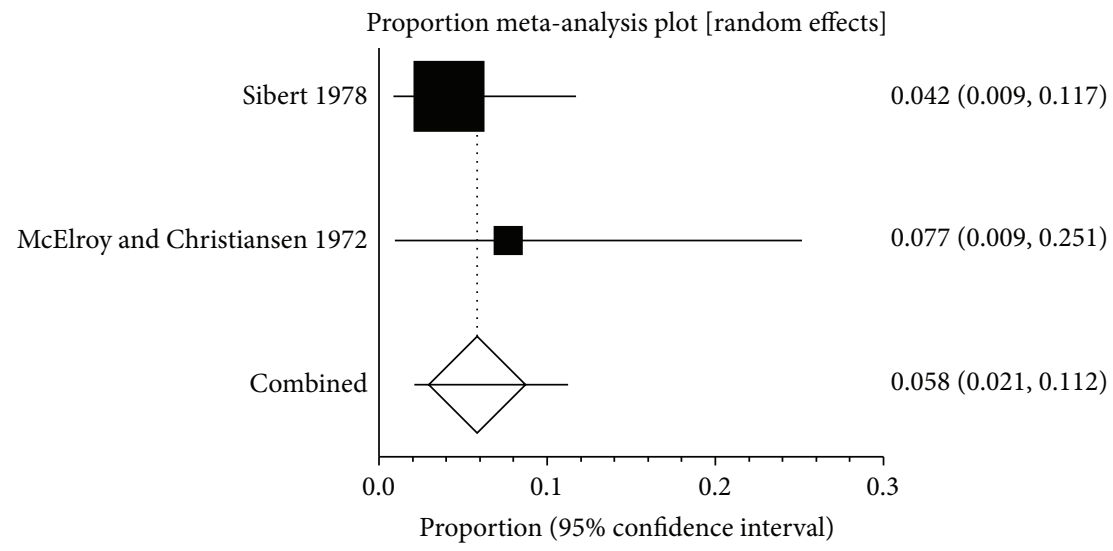

(c)

FIGURE 6: (a) Forest plots showing the prevalence of splanchnic vein thrombosis (SVT) in hereditary pancreatitis (HP). (b) Forest plots showing the prevalence of portal vein thrombosis (PVT) in hereditary pancreatitis (HP). (c) Forest plots showing the prevalence of splenic vein thrombosis (SlpVT) in hereditary pancreatitis (HP).

(Figure 1). Additionally, five studies recorded by the same study team in different publications were excluded [8-12] and one study which concerned the same patients by the same first author in different publications was also excluded [13]. Another study was excluded because the number of participants was $<10$ [14]. Twenty-two of 44 studies were conducted in Europe [6,15-35], fourteen in America [2, 5, 7, 36-46], and eight in Asia [47-54]. Among 10441 participants, 874 patients with SVT were screened. These patients included 197 patients with PVT, 525 with SplV, and 72 with MVT. The detailed characteristics of these included studies were shown in Table 1. 


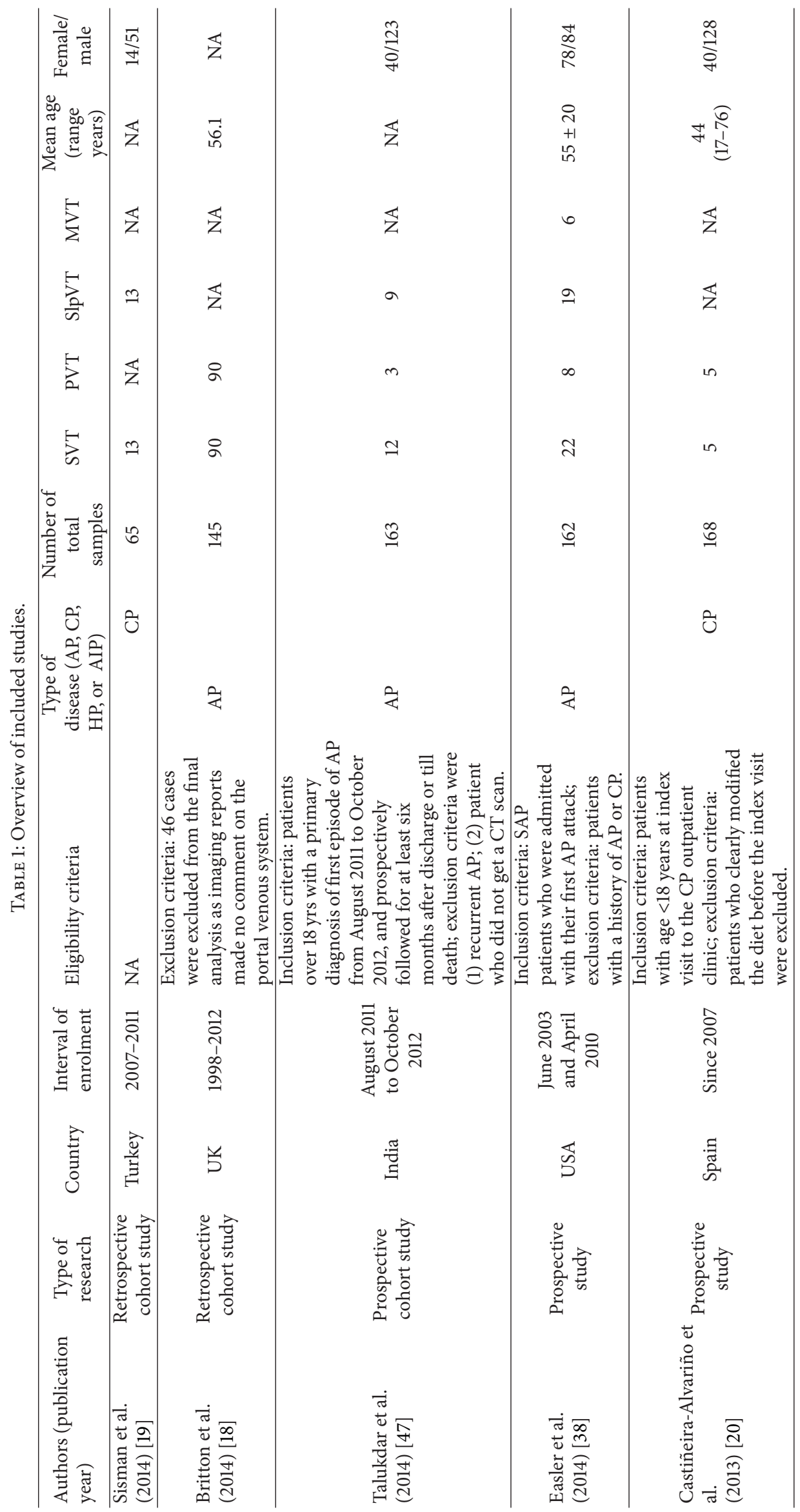




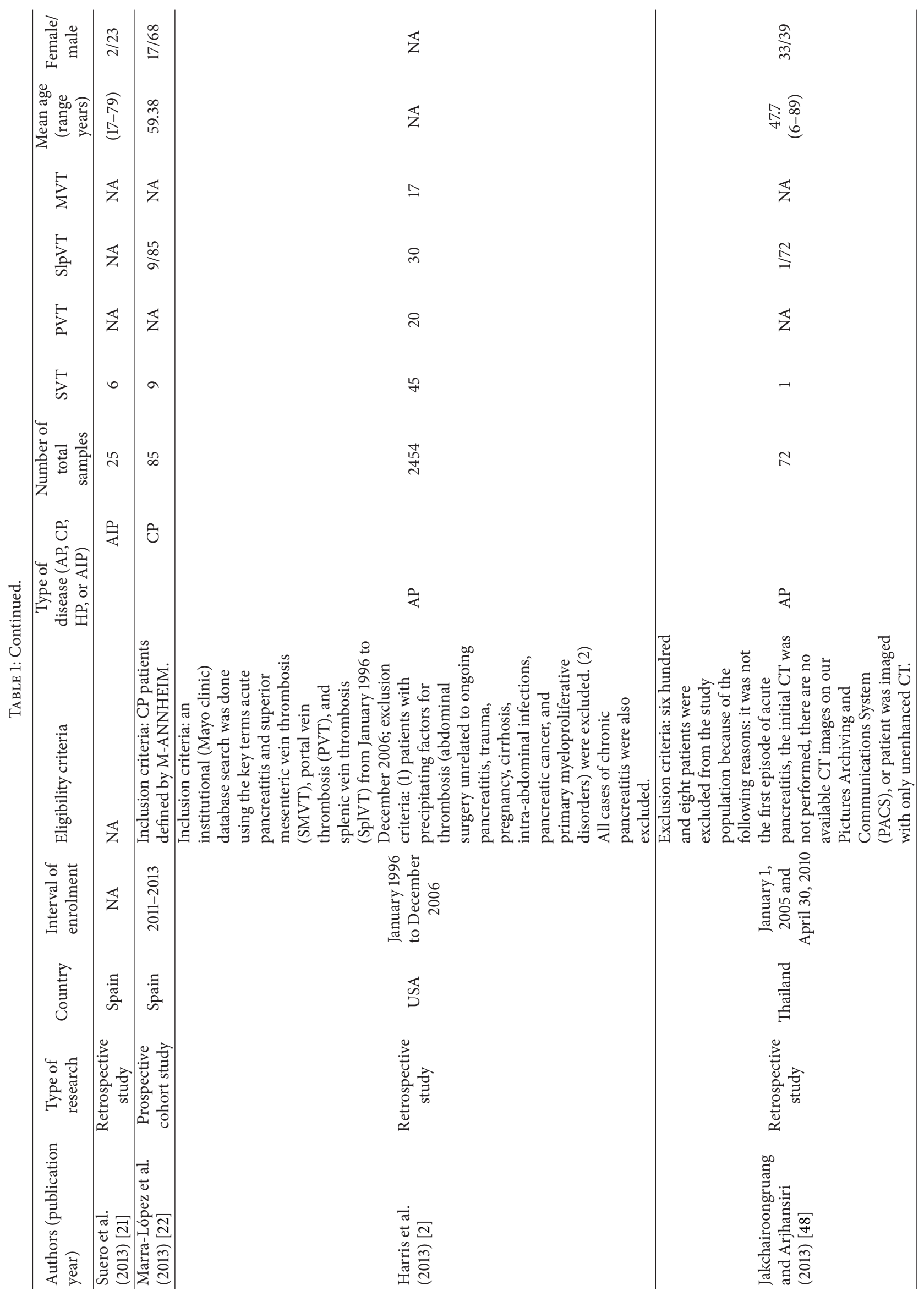




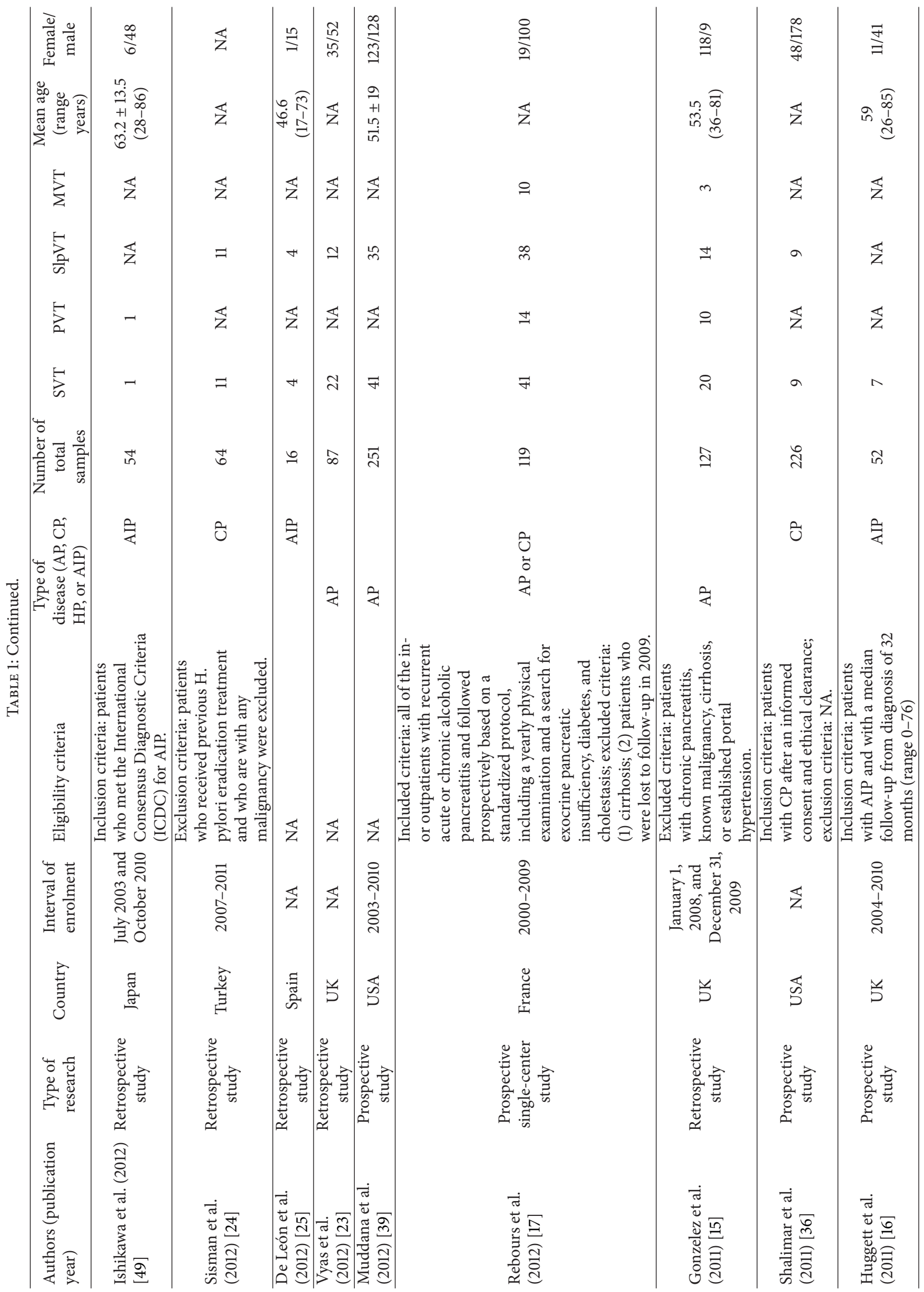




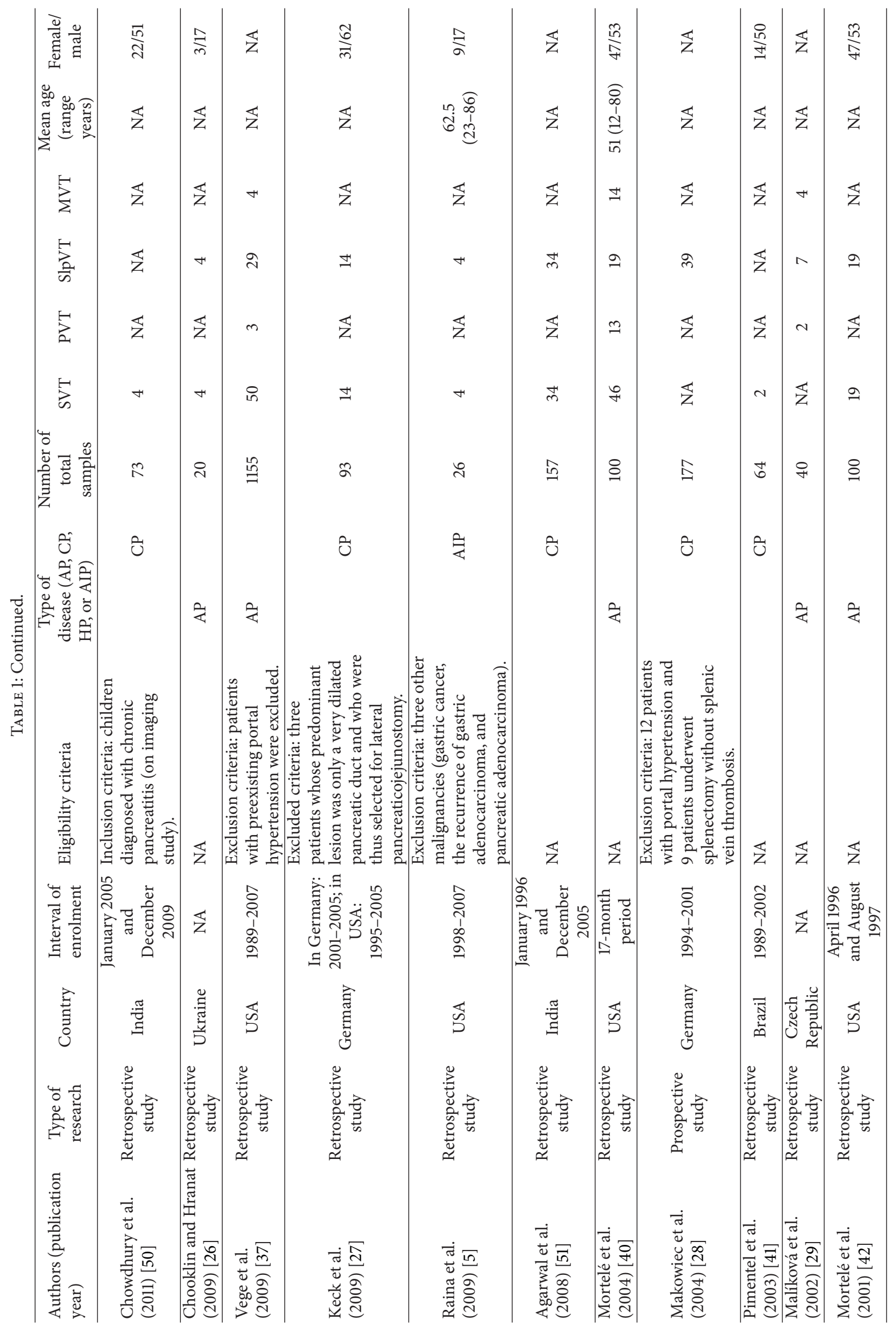




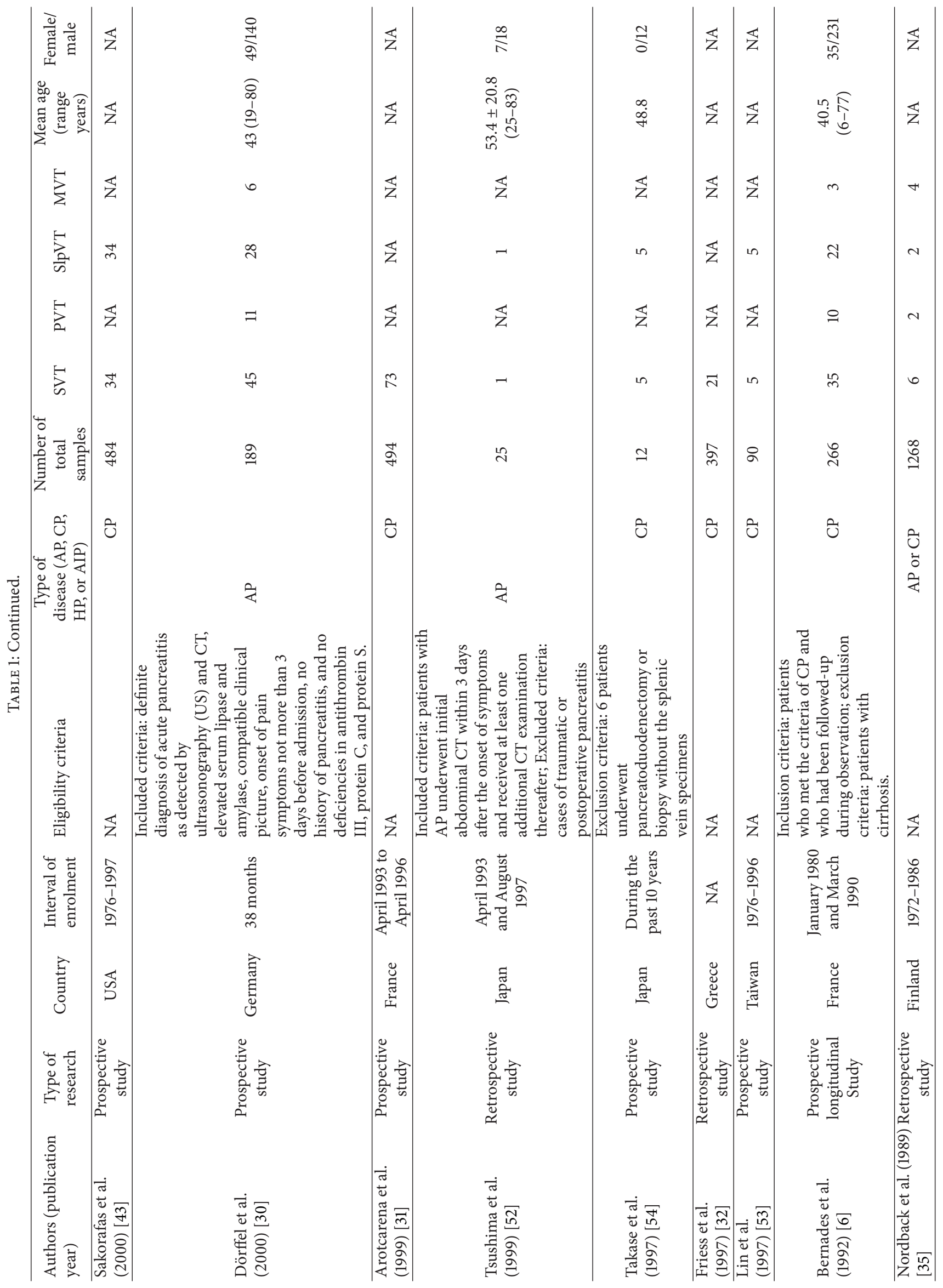




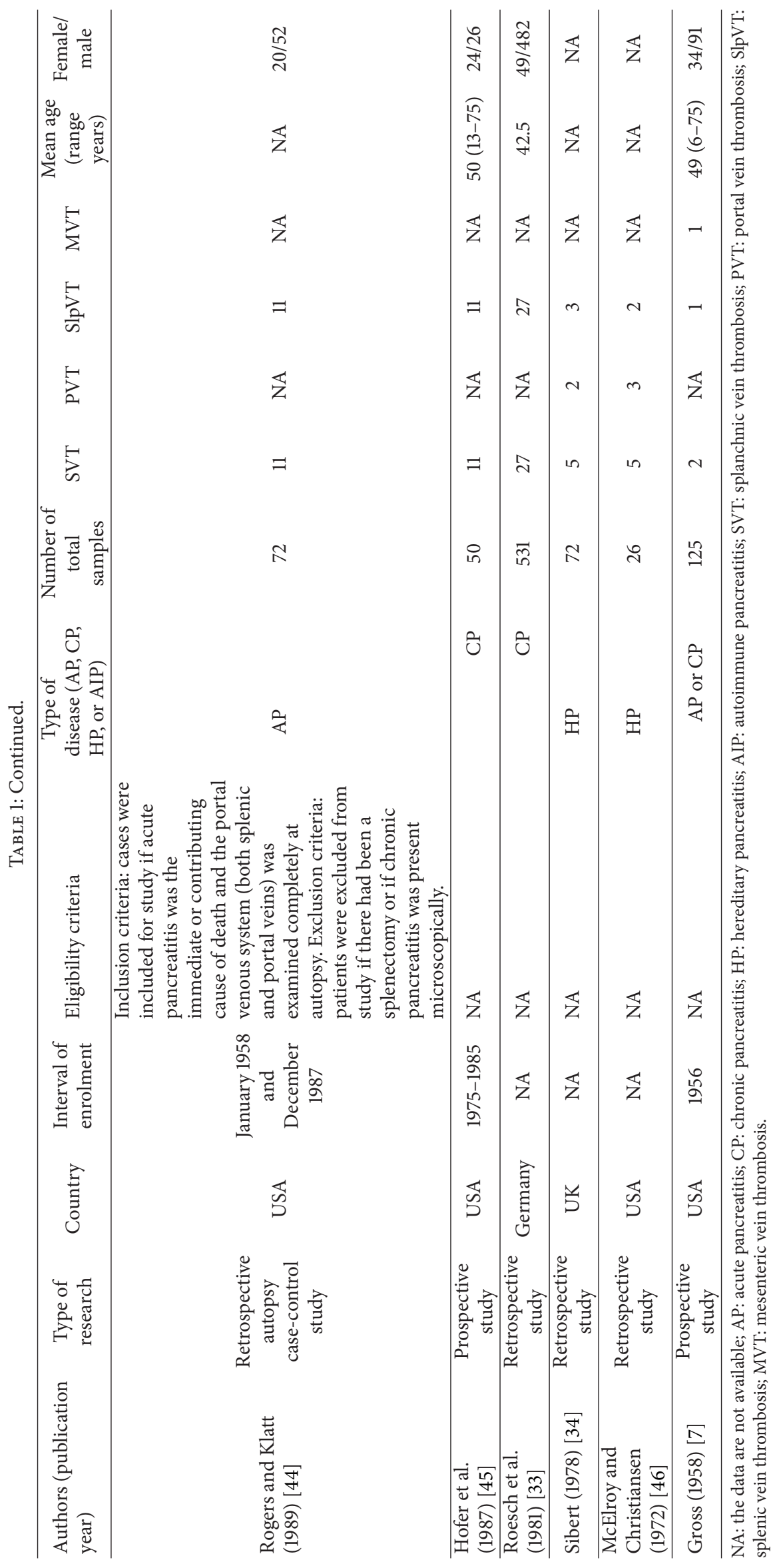


Proportion meta-analysis plot [random effects]

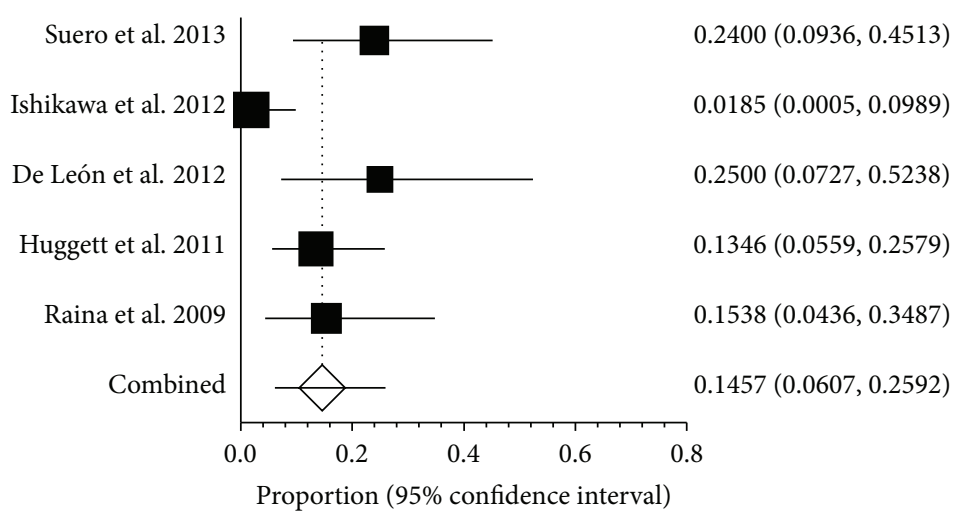

(a)

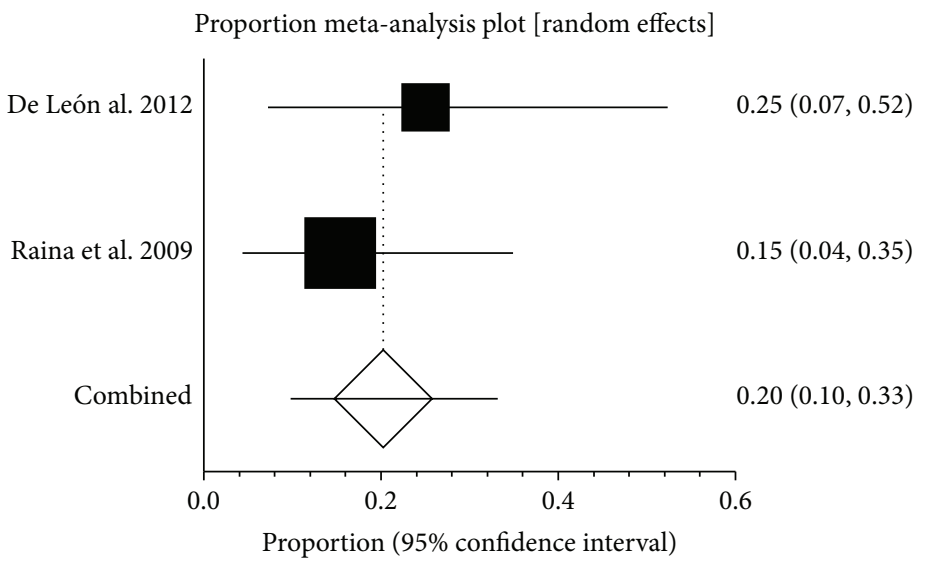

(b)

FIGURE 7: (a) Forest plots showing the prevalence of splanchnic vein thrombosis (SVT) in autoimmune pancreatitis (AIP). (b) Forest plots showing the prevalence of splenic vein thrombosis (SlpVT) in autoimmune pancreatitis (AIP).

3.2. Quality of the Included Studies. The involved countries of all studies could be found. Interval of enrolment was unavailable in ten of the 44 studies. Twenty-one studies had no eligibility criteria; eight of the remaining 23 studies had detailed inclusion and exclusion criteria. Demographic data were completely recorded in nineteen studies. The pancreatitis diagnostic criteria were not elaborate in nine studies only with abstracts and one study with full-test.

3.3. Prevalence of SVT in Pancreatitis. A meta-analysis of involved studies meeting eligibility criteria showed the prevalence of SVT in patients with pancreatitis, ranging from $0.5 \%$ to $62.1 \%$ (Figure 2 ). A pooled prevalence was $13.6 \%(95 \%$ CI: $10.2 \%-17.4 \%)$ with a statistically significant heterogeneity among studies $\left(I^{2}=96.2 \%, 95 \%\right.$ CI: 95.7\%-96.6\%, $P<$ $0.001)$.

3.4. Prevalence of PVT, SplVT, and MVT in Pancreatitis. Seventeen studies reported the prevalence of PVT in patients with pancreatitis, ranging from $0.2 \%$ to $62.1 \%$ (Figure $3(\mathrm{a})$ ). A pooled prevalence was $6.2 \%$ (95\% CI: $32.9 \%-10.7 \%)$ with a statistically significant heterogeneity among studies $\left(I^{2}=\right.$
97.1\%, 95\% CI: 96.6\%-97.6\%, $P<0.001)$. The analysis of patients with SplVT in pancreatitis showed that the prevalence ranged from $0.2 \%$ to $41.7 \%$ (Figure $3(\mathrm{~b})$ ). A pooled prevalence was $11.2 \%$ (95\% CI: $8.1 \%-14.7 \%)$ with a statistically significant heterogeneity among studies $\left(I^{2}=95.2 \%, 95 \% \mathrm{CI}\right.$ : $94.4 \%-95.8 \%, P<0.001)$. Eleven studies were selected to analyze the prevalence of MVT in pancreatitis, ranging from $0.3 \%$ to $14 \%$ (Figure $3(\mathrm{c})$ ). The pooled prevalence was $2.7 \%$ (95\% CI: $1.4 \%-4.4 \%)$ and the heterogeneity remained $\left(I^{2}=\right.$ $89.3 \%$, 95\% CI: 83.2\%-92.5\%).

3.5. Prevalence of SVT in AP and CP. Eighteen studies reported the prevalence of SVT in AP, ranging from $0.3 \%$ to $62.1 \%$ (Figure $4(\mathrm{a})$ ). The pooled prevalence was $16.6 \%(95 \%$ CI: $10.0 \%-24.5 \%)$ with a statistically significant heterogeneity among studies $\left(I^{2}=98 \%\right.$, 95\% CI: 97.7\%-98.2\%, $\left.P<0.001\right)$. Nine studies reported the prevalence of PVT in AP, ranging from $0.3 \%$ to $62.1 \%$ (Figure $4(\mathrm{~b})$ ). The pooled prevalence was $8.0 \%$ (95\% CI: $2.4 \%-16.4 \%)$ with a statistically significant heterogeneity among studies $\left(I^{2}=98.2 \%\right.$, 95\% CI: $97.8 \%-$ 98.5\%, $P<0.001)$. Fifteen studies reported the prevalence of SplVT in AP, ranging from $1.2 \%$ to $20 \%$ (Figure $4(\mathrm{c})$ ). 
Proportion meta-analysis plot (random effects)

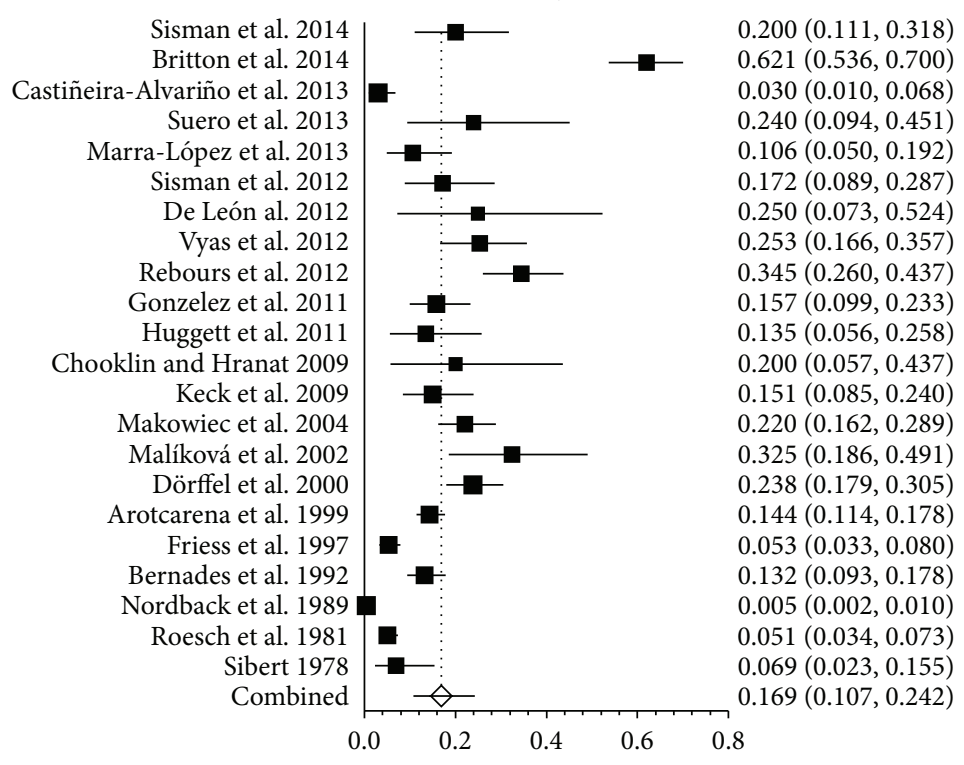

Proportion (95\% confidence interval)

(a)

Proportion meta-analysis plot (random effects)

Britton et al. 2014

Castiñeira-Alvariño et al. 2013

Rebours et al. 2012

Gonzelez et al. 2011

Malíková et al. 2002

Dörffel et al. 2000

Bernades et al. 1992

Nordback et al. 1989 Sibert 1978 Combined

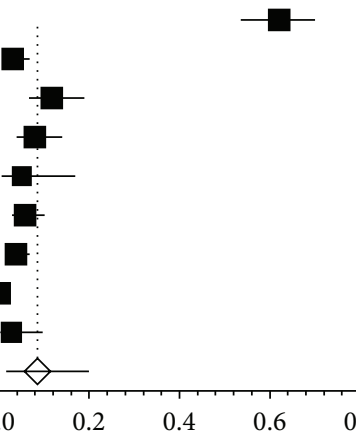

Proportion (95\% confidence interval)

(b)

(b)
$0.6207(0.5364,0.6999)$

$0.0298(0.0097,0.0681)$

$0.1176(0.0658,0.1895)$

$0.0787(0.0384,0.1400)$

$0.0500(0.0061,0.1692)$

$0.0582(0.0294,0.1017)$

$0.0376(0.0182,0.0680)$

$0.0016(0.0002,0.0057)$

$0.0278(0.0034,0.0968)$

$0.0846(0.0163,0.1990)$

Proportion meta-analysis plot (random effects)

Sisman et al. 2014

Marra-López et al. 2013

Sisman et al. 2012

De León al. 2012

Vyas et al. 2012

Rebours et al. 2012

Gonzelez et al. 2011

Chooklin and Hranat 2009

Keck et al. 2009

Makowiec et al. 2004

Malíková et al. 2002

Dörffel et al. 2000

Bernades et al. 1992

Nordback et al. 1989

Roesch et al. 1981 Sibert 1978

Combined

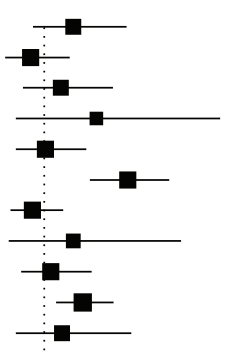

$0.2000(0.1110,0.3177)$

$0.1059(0.0496,0.1915)$

$0.1719(0.0890,0.2868)$

$0.2500(0.0727,0.5238)$

$0.1379(0.0734,0.2285)$

$0.3193(0.2369,0.4110)$

$0.1102(0.0616,0.1780)$

$0.2000(0.0573,0.4366)$

$0.1505(0.0848,0.2397)$

$0.2203(0.1616,0.2887)$

$0.1750(0.0734,0.3278)$

$0.1481(0.1008,0.2069)$

$0.0827(0.0526,0.1225)$

$0.0016(0.0002,0.0057)$

$0.0508(0.0338,0.0731)$

$0.0417(0.0087,0.1170)$

$0.1352(0.0756,0.2086)$

$$
\begin{array}{lllll}
0.0 & 0.2 & 0.4 & 0.6 & 0.8
\end{array}
$$

Proportion (95\% confidence interval)

(c)

Figure 8: Continued. 


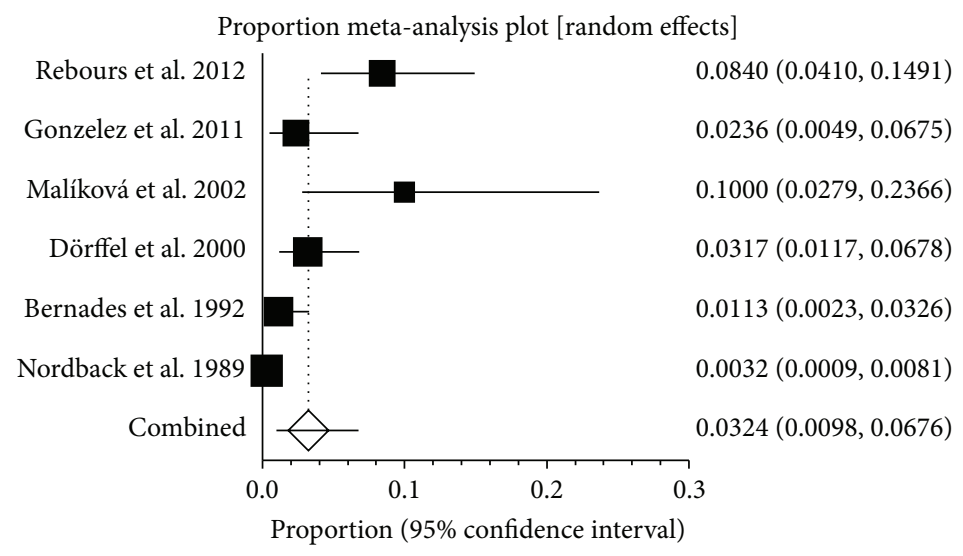

(d)

FIGURE 8: (a) Forest plots showing the prevalence of splanchnic vein thrombosis (SVT) in Europe. (b) Forest plots showing the prevalence of portal vein thrombosis (PVT) in Europe. (c) Forest plots showing the prevalence of splenic vein thrombosis (SlpVT) in Europe. (d) Forest plots showing the prevalence of mesenteric vein thrombosis (MVT) in Europe.

The pooled prevalence was $10.4 \%$ (95\% CI: $6.3 \%-15.3 \%)$ with a statistically significant heterogeneity among studies $\left(I^{2}=\right.$ 94.8\%, 95\% CI: 93.3\%-95.8\%, $P<0.001)$. Eight studies reported the prevalence of MVT in pancreatitis, ranging from $0.3 \%$ to $14.0 \%$ (Figure $4(\mathrm{~d})$ ). The pooled prevalence was $2.6 \%$ (95\% CI: $1.2 \%-4.5 \%)$ with a statistically significant heterogeneity among studies $\left(I^{2}=90.4 \%\right.$, 95\% CI: $83.9 \%-$ 93.6\%, $P<0.001)$.

Twenty studies reported the prevalence of SVT in CP, ranging from $3 \%$ to $41.7 \%$ (Figure $5(\mathrm{a})$ ). The pooled prevalence was $11.6 \%$ (95\% CI: $8.5 \%-15.1 \%)$ with a statistically significant heterogeneity among studies $\left(I^{2}=89.5 \%, 95 \% \mathrm{CI}\right.$ : $85.6 \%-91.9 \%, P<0.001)$. Four studies reported the prevalence of PVT in CP, ranging from $1.5 \%$ to $4 \%$ (Figure $5(\mathrm{~b})$ ). The pooled prevalence was 3.5\% (95\% CI: $2.3 \%-4.8 \%)$ and there was no statistical heterogeneity between the two studies $\left(I^{2}=0 \%\right.$, 95\% CI: $\left.0 \%-67.9 \%, P=0.5947\right)$. Thirteen studies reported the prevalence of SplVT in CP, ranging from $1.5 \%$ to $41.7 \%$ (Figure $5(\mathrm{c})$ ). The pooled prevalence was 12.8\% (95\% CI: $8.7 \%-17.6 \%)$ with a statistically significant heterogeneity among studies $\left(I^{2}=88.8 \%\right.$, 95\% CI: $83 \%-$ $91.9 \%, P<0.001)$. Two studies reported the prevalence of MVT in pancreatitis, ranging from $0.8 \%$ to $1.1 \%$ (Figure $5(\mathrm{~d})$ ). The pooled prevalence was $1.2 \%$ (95\% CI: $0.4 \%-2.5 \%)$. There was no statistical heterogeneity between the two studies $(P=$ $0.8506)$.

3.6. Prevalence of SVT in HP and AIP. Only two studies reported the prevalence of SVT in HP, ranging from $7 \%$ to $19 \%$ (Figure 6(a)). The pooled prevalence was $12.2 \%(95 \%$ CI: $3.0 \%-26.5 \%)$ and there was no statistical heterogeneity between the two studies $(P=0.0914)$. Two studies reported the prevalence of PVT in HP, ranging from $2.8 \%$ to $11.5 \%$ (Figure 6(b)). The pooled prevalence was $6.6 \%(95 \%$ CI: $0.7 \%-17.8 \%)$ and there was no statistical heterogeneity between the two studies $(P=0.1056)$. Two studies reported the prevalence of SplVT in HP, ranging from $4.2 \%$ to $7.7 \%$
(Figure 6(c)). The pooled prevalence was 5.8\% (95\% CI: $2.1 \%-$ $11.2 \%)$ and there was no statistical heterogeneity between the two studies $(P=0.437)$. There was no data on the prevalence of MVT in HP.

Five studies reported the prevalence of SVT in AIP, ranging from $1.9 \%$ to $25 \%$ (Figure $7(\mathrm{a})$ ). The pooled prevalence was $14.6 \%$ (95\% CI: $6.1 \%-25.9 \%)$ and there was no statistical heterogeneity between the two studies $\left(I^{2}=71.4 \%, 95 \% \mathrm{CI}\right.$ : $0 \%-86.7 \%, P=0.0074)$. Two studies reported the prevalence of SplVT in AIP, ranging from $15 \%$ to $25 \%$ (Figure $7(\mathrm{~b})$ ). The pooled prevalence was $20.2 \%$ (95\% CI: $9.8 \%-33.2 \%$ ) and there was no statistical heterogeneity between the two studies $(P=0.4388)$. Only one study reported that the prevalence of PVT in AIP was 1.9\%. There was no data on the prevalence of MVT in AIP.

3.7. Prevalence of SVT in Pancreatitis in Different Continent. The involved countries of all studies could be divided into three continents (Europe, America, and Asia). The incidences of SVT in pancreatitis were different among three continents. In Europe, twenty-two studies reported the prevalence of pancreatitis patients with SVT, ranging from $0.5 \%$ to $62.1 \%$ (Figure $8(\mathrm{a})$ ). The pooled prevalence was $16.9 \%$ (95\% CI: $10.7 \%-24.2 \%)$ with a statistically significant heterogeneity among studies $\left(I^{2}=97 \%\right.$, 95\% CI: 96.6\%-97.4\%, $P<$ $0.001)$. Nine studies reported the prevalence of PVT in pancreatitis, ranging from $0.2 \%$ to $62.1 \%$ (Figure $8(\mathrm{~b})$ ). The pooled prevalence was $8.5 \%$ (95\% CI: $1.6 \%-19.9 \%)$ with a statistically significant heterogeneity among studies $\left(I^{2}=\right.$ 98.1\%, 95\% CI: 97.7\%-98.4\%). Sixteen studies reported the prevalence of SplVT in pancreatitis, ranging from $0.2 \%$ to $31.9 \%$ (Figure 8(c)). The pooled prevalence was 13.5\% (95\% CI: 7.6\%-20.9\%) with a statistically significant heterogeneity among studies $\left(I^{2}=96.2 \%\right.$, 95\% CI: 95.3\%-96.8\%, $P<$ $0.001)$. Six studies reported the prevalence of MVT in pancreatitis, ranging from $0.3 \%$ to $10 \%$ (Figure $8(\mathrm{~d})$ ). The pooled prevalence was $3.2 \%$ (95\% CI: $1.0 \%-6.8 \%)$ with a statistically 


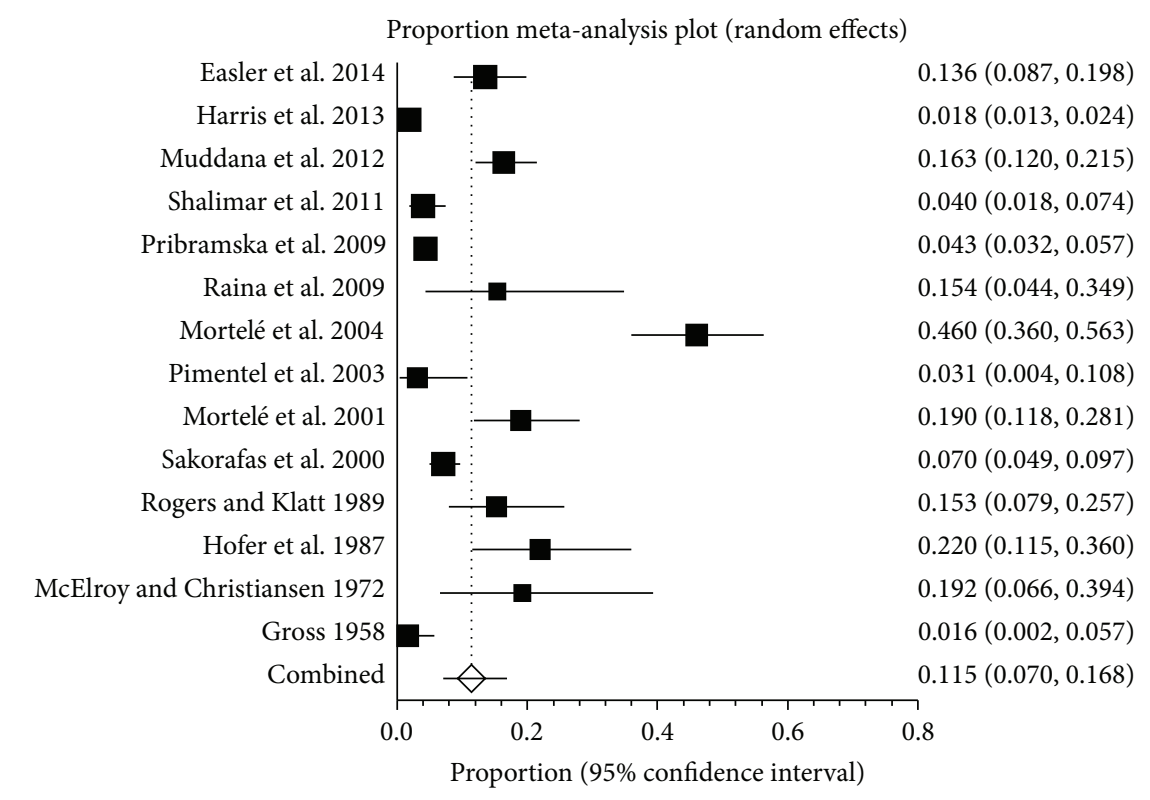

(a)

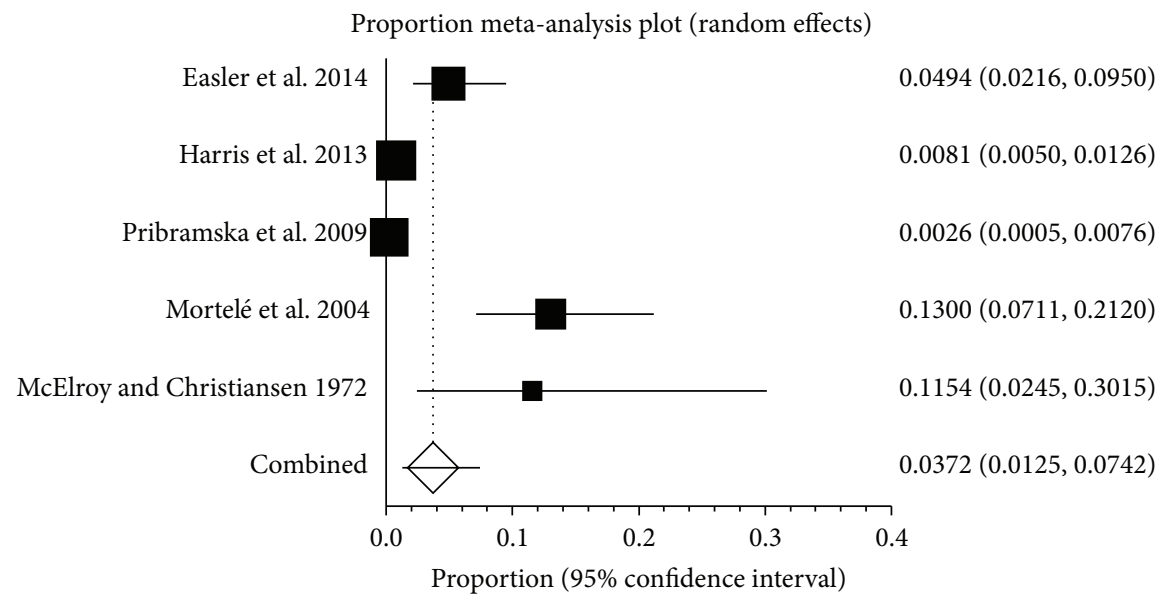

(b)

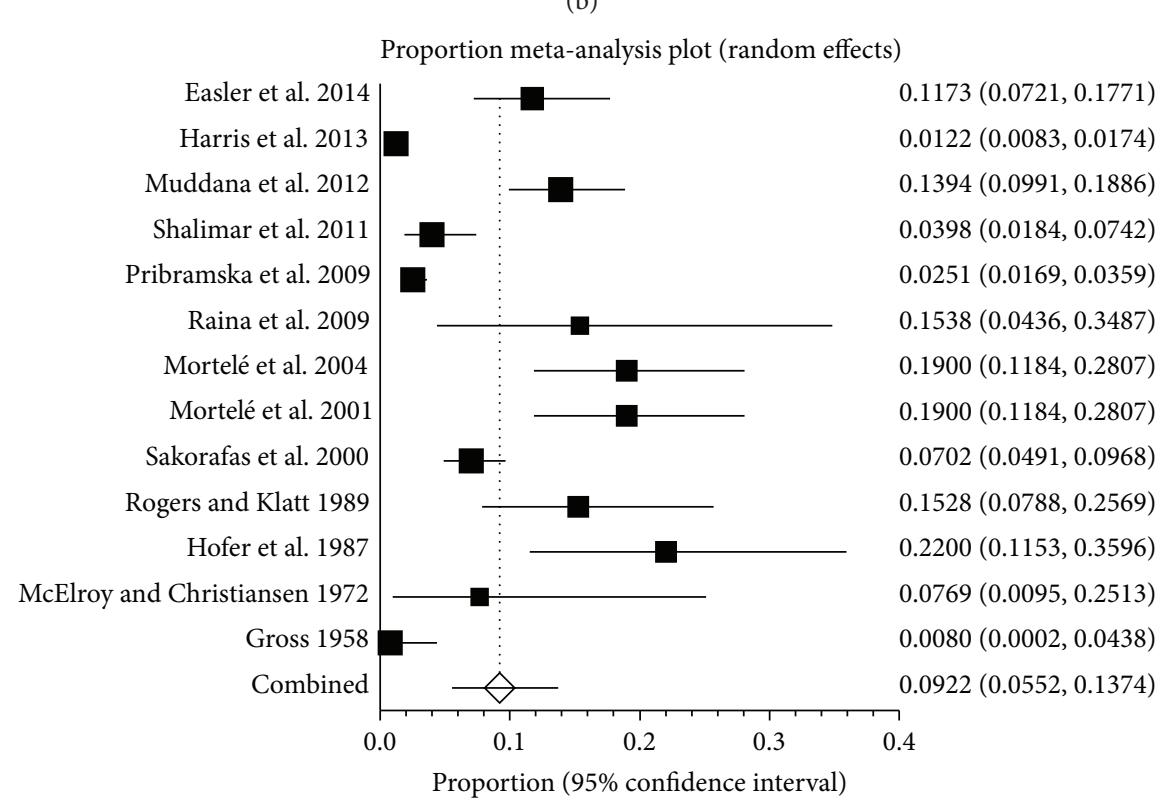

(c)

Figure 9: Continued. 


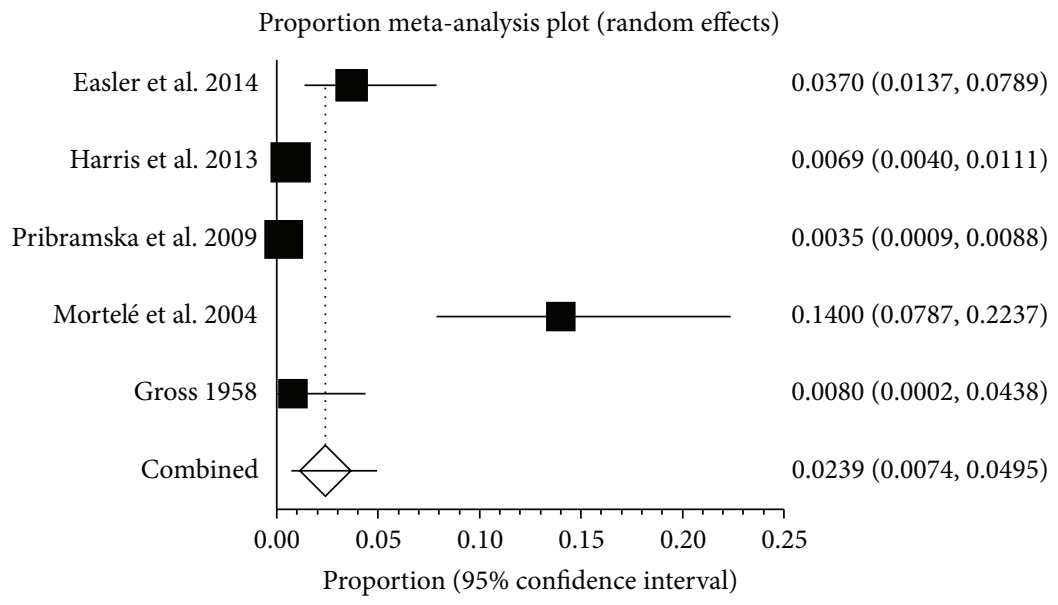

(d)

FIGURE 9: (a) Forest plots showing the prevalence of splanchnic vein thrombosis (SVT) in America. (b) Forest plots showing the prevalence of portal vein thrombosis (PVT) in America. (c) Forest plots showing the prevalence of splenic vein thrombosis (SlpVT) in America. (d) Forest plots showing the prevalence of mesenteric vein thrombosis (MVT) in America.

significant heterogeneity among studies $\left(I^{2}=88.8 \%, 95 \% \mathrm{CI}\right.$ : $77.4 \%-93.1 \%, P<0.001)$.

In America, fourteen studies reported the prevalence of SVT in pancreatitis, ranging from $1.6 \%$ to $46 \%$ (Figure $9(\mathrm{a})$ ). The pooled prevalence was $11.5 \%$ (95\% CI: 7.0\%-16.8\%) with a statistically significant heterogeneity among studies $\left(I^{2}=\right.$ 95.7\%, 95\% CI: 94.6\%-96.5\%, $P<0.001)$. Five studies reported the prevalence of PVT in pancreatitis, ranging from $0.3 \%$ to $13 \%$ (Figure $9(\mathrm{~b})$ ). The pooled prevalence was $3.7 \%$ (95\% CI: $1.3 \%-7.4 \%)$ with a statistically significant heterogeneity among studies $\left(I^{2}=93.2 \%\right.$, 95\% CI: 87.6\%-95.6\%, $P<0.001)$. Thirteen studies reported the prevalence of SplVT in pancreatitis, ranging from $0.8 \%$ to $22 \%$ (Figure 9 (c)). The pooled prevalence was $9.2 \%$ (95\% CI: 5.5\%-13.7\%) with a statistically significant heterogeneity among studies $\left(I^{2}=\right.$ 94.8\%, 95\% CI: 93.2\%-95.9\%, $P<0.001)$. Five studies reported the prevalence of MVT in pancreatitis, ranging from $0.4 \%$ to $14 \%$ (Figure $9(\mathrm{~d})$ ). The pooled prevalence was $2.4 \%$ (95\% CI: $0.7 \%-5.0 \%)$ with a statistically significant heterogeneity among studies $\left(I^{2}=91.7 \%\right.$, 95\% CI: $83.6 \%-$ 94.8\%, $P<0.001)$.

In Asia, eight studies reported the prevalence of SVT in pancreatitis, ranging from $1.4 \%$ to $41.7 \%$ (Figure $10(\mathrm{a})$ ). The pooled prevalence was $8.5 \%$ (95\% CI: 3.7\%-15.1\%) with a statistically significant heterogeneity among studies $\left(I^{2}=\right.$ 84.2\%, 95\% CI: $68.5 \%-90.3 \%, P<0.001)$. Two studies reported the prevalence of PVT in pancreatitis, ranging from $1.8 \%$ to $1.9 \%$ (Figure $10(\mathrm{~b})$ ). The pooled prevalence in two studies was $2.3 \%$ (95\% CI: $0.7 \%-4.6 \%)$. Six studies reported the prevalence of SplVT in pancreatitis, ranging from $1.4 \%$ to $41.7 \%$ (Figure 10(c)). The pooled prevalence was 10.1\% (95\% CI: $3.6 \%-19.5 \%)$ with a statistically significant heterogeneity among studies $\left(I^{2}=87.8 \%\right.$, 95\% CI: $\left.74.5 \%-92.6 \%, P<0.001\right)$. There was no data on the prevalence of MVT in pancreatitis in Asia.

\section{Discussion}

The previous published meta-analysis that assessed the prevalence of SVT in patients with pancreatitis almost focused on AP, CP, HP, or AIP alone without systematic search. The prevalence varied from $1 \%$ to $24 \%$ in previous studies according to the type of pancreatitis and imaging technique used (US, EUS, CT, MRI, or ERCP) [30, 40, 55]. However, our study was remarkably different from the previous ones, as follows. (1) In the previous studies, most of them were singlecenter studies with a limited enrollment period and target population. By comparison, our meta-analysis included all studies conducted from 1958 to 2014 and 10560 patients with pancreatitis. Furthermore, we made a distinction on the source of patients according to the continents. (2) As we have known, SVT involves PVT, SplVT, and MVT. In contrast to the previous studies, we have paid more attention on the prevalence of PVT, SplVT, and MVT in pancreatitis. (3) Our research reported the prevalence of SVT on the basis of the different types of pancreatitis including AP, CP, HP, and AIP. However, there was no similar record in the previous studies.

Pancreatitis is associated with a variety of vascular complications including SVT. Clinically, SVT in pancreatitis is becoming common with the advancement of imaging technique. In the current systematic review and meta-analysis, we demonstrated that $13.6 \%$ of pancreatitis had SVT, $6.2 \%$ had PVT, $11.2 \%$ had SplVT, and $2.7 \%$ had MVT. The prevalence of SVT in pancreatitis showed some regional differences. We found that the prevalence of SVT in pancreatitis in Europe reached $16.9 \%$, which was the highest among the three continents. Moreover, the prevalence of PVT, SplVT, and MVT in pancreatitis in Europe was higher than that in America or in Asia, respectively. We can find from the involved studies that the results came from nine countries of Europe, which were more than those from four of Asia and 


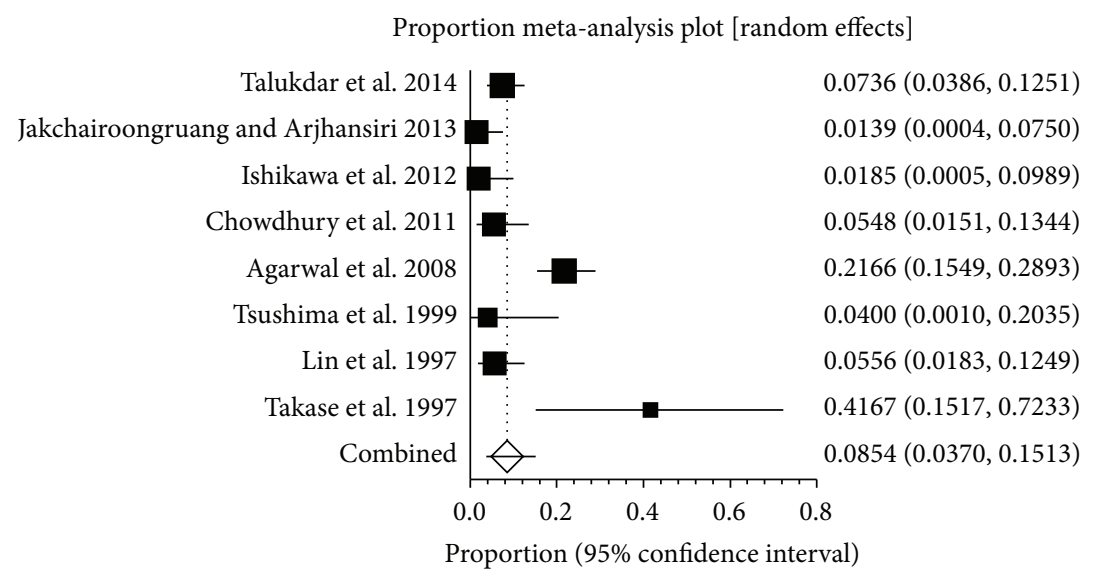

(a)

Proportion meta-analysis plot (random effects)

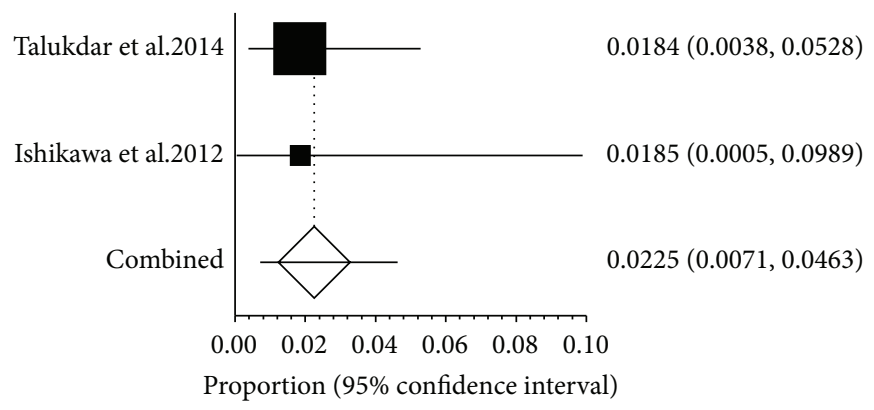

(b)

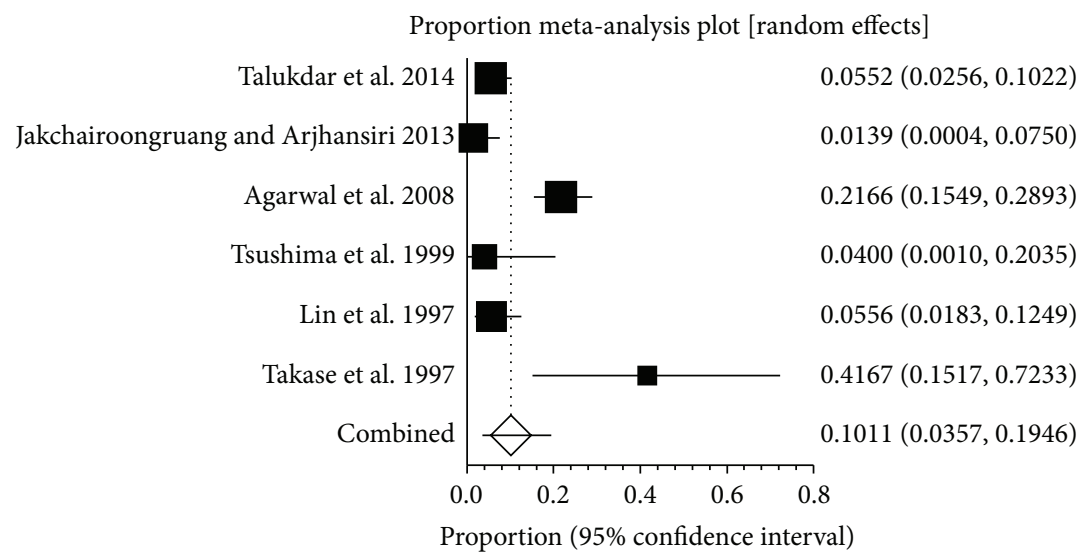

(c)

FIGURE 10: (a) Forest plots showing the prevalence of splanchnic vein thrombosis (SVT) in Asia. (b) Forest plots showing the prevalence of portal vein thrombosis (PVT) in Asia. (c) Forest plots showing the prevalence of splenic vein thrombosis (SlpVT) in Asia.

two of America. Compared with Asia, the prevalence of SVT in pancreatitis was $11.5 \%$ higher than that of $8.5 \%$ in Asia, but the prevalence of SplVT was a little lower in America.

Previous studies that reported the vascular complications of pancreatitis showed different prevalence of SVT in pancreatitis regardless of the type of pancreatitis. This meta-analysis demonstrated that the prevalence of SVT in AP was $16.6 \%$ higher than previous studies with a reported incidence of $1-2 \%$ [1]. The reason was that previous studies took PVT, SplVT, and MVT inclusion of SVT as numerator.
The controversy also exists about the prevalence of SplVT in CP. The old series reported that the prevalence of SplVT in patients with CP varied between $2.5 \%$ and $25 \%[6,51,56,57]$. Our results showed $12.8 \%$ CP with SplVT, which was similar to that from a recent report by Butler et al. [58]. However, there was no detailed description on the prevalence of SVT in HP and AIP. Our results showed that the prevalence of SVT was $12.2 \%$ and $14.6 \%$ in HP and AIP, respectively. All of these could enrich the whole research on the prevalence of SVT in pancreatitis. 


\section{Limitation}

Our study has several limitations. Firstly, the heterogeneity of available data from various years' studies was significant. Depending on advanced imaging technique, the majority of asymptomatic patients with SVT could be involved in research groups. Therefore, only the random-effects model was applied in our meta-analysis to generate a more conservative estimate of the proportion. Secondly, there are different results between Western and Asian countries. Besides the difference in the population race, lifestyle, and diagnostic level, the number of countries involved in the research is different. America included two countries and four countries were from Asia. Thirdly, there is no related research on the prevalence of SVT in HP and AIP. The final results may be not so typical.

\section{Conclusion}

This systematic review and meta-analysis attempt to quantify the incidence of SVT in pancreatitis according to the different forms of pancreatitis and regional distribution. Further studies are needed to analyze the relationship between natural history, clinical significance, long-term outcomes, and the prevalence of SVT in pancreatitis. The rate of SVT associated gastrointestinal bleeding and the security and reasonability of anticoagulation therapy on thrombosis are all needed to develop complete, large, multicentre, and collaborative studies.

\section{Conflict of Interests}

The authors declare that there is no conflict of interests regarding the publication of this paper.

\section{References}

[1] I. H. Mallick and M. C. Winslet, "Vascular complications of pancreatitis," Journal of the Pancreas, vol. 5, no. 5, pp. 328-337, 2004.

[2] S. Harris, N. A. Nadkarni, H. V. Naina, and S. S. Vege, "Splanchnic vein thrombosis in acute pancreatitis: a single-center experience," Pancreas, vol. 42, no. 8, pp. 1251-1254, 2013.

[3] D. F. Stroup, J. A. Berlin, S. C. Morton et al., "Meta-analysis of observational studies in epidemiology: a proposal for reporting," JAMA, vol. 283, no. 15, pp. 2008-2012, 2000.

[4] J. P. T. Higgins, S. G. Thompson, J. J. Deeks, and D. G. Altman, "Measuring inconsistency in meta-analyses," British Medical Journal, vol. 327, no. 7414, pp. 557-560, 2003.

[5] A. Raina, D. Yadav, A. M. Krasinskas et al., "Evaluation and management of autoimmune pancreatitis: experience at a large US center," The American Journal of Gastroenterology, vol. 104, no. 9, pp. 2295-2306, 2009.

[6] P. Bernades, A. Baetz, P. Lévy, J. Belghiti, Y. Menu, and F. Fekete, "Splenic and portal venous obstruction in chronic pancreatitis. A prospective longitudinal study of a medical-surgical series of 266 patients," Digestive Diseases and Sciences, vol. 37, no. 3, pp. 340-346, 1992.

[7] J. B. Gross, "Some recent developments pertaining to pancreatitis," Annals of Internal Medicine, vol. 49, no. 4, pp. 796-819, 1958.
[8] H. D. Gonzalez et al., "Splanchnic vein thrombosis in severe acute pancreatitis-is systemic anticoagulation indicated? Pancreatology," Pancreatology, vol. 11, no. 3, p. 314, 2011.

[9] S. Shalimar, S. Midha, P. Bhardwaj, and P. K. Garg, "Long-term pain relief with optimized medical therapy including antioxidants in patients with chronic pancreatitis," Pancreatology, vol. 11, p. 32, 2011.

[10] M. T. Huggett, K. Tang, G. J. Johnson, A. R. Hatfield, S. P. Pereira, and G. J. Webster, "Disease profile and long-term outcome of patients with autoimmune pancreatitis/IgG4 systemic disease," Gastroenterology, vol. 140, supplemet 1, no. 5, p. S-545, 2011.

[11] V. Rebours, M. Vullierme, and B. Condat, "Digestive venous thrombosis (DVT) occuring during chronic pancreatitis is caused by local inflammation and not by thrombophilia," Pancreatology, vol. 10, no. 2-3, p. 275, 2010.

[12] V. Pribramska, S. S. Vege, J. Trna, P. S. Kamath, and S. T. Chari, "Natural history of splanchnic venous thrombosis in acute pancreatitis: a population-based study," Gastroenterology, vol. 136, no. 5, supplement 1, p. A-541, 2009.

[13] V. Rebours, M. P. Vullierme, B. Condat et al., "Digestive venous thrombosis (DVT) occurring during alcoholic acute or chronic pancreatitis is caused by local inflmmation and not by thrombophilia," Gastroenterology, vol. 138, no. 5, supplement 1, p. S392, 2010.

[14] J. A. Lawson, "A Dutch family with hereditary pancreatitis," Nederlands Tijdschrift voor Geneeskunde, vol. 125, no. 8, pp. 304312, 1981.

[15] H. J. Gonzelez, S. J. Sahay, B. Samadi, B. R. Davidson, and S. H. Rahman, "Splanchnic vein thrombosis in severe acute pancreatitis: a 2-year, single-institution experience," $H P B$, vol. 13, no. 12, pp. 860-864, 2011.

[16] M. T. Huggett, K. Tang, G. J. Johnson, A. R. Hatfild, S. P. Pereira, and G. J. Webster, "Disease profie and long-term outcome of patients with autoimmune pancreatitis/IgG4 systemic disease," Gut, vol. 60, supplemet 1, p. A8, 2011.

[17] V. Rebours, L. Boudaoud, M.-P. Vullierme et al., "Extrahepatic portal venous system thrombosis in recurrent acute and chronic alcoholic pancreatitis is caused by local inflammation and not thrombophilia," The American Journal of Gastroenterology, vol. 107, no. 10, pp. 1579-1585, 2012.

[18] E. Britton, S. Mahoney, J. Garry, C. Halloran, and P. Richardson, "PTH-095 portal hypertension due to splanchnic venous thrombosis following open or skunk wire necrosectomy of acute severe pancreatitis," Gut, vol. 63, supplement 1, p. A252, 2014.

[19] G. Sisman, Y. Erzin, I. Hatemi et al., "Familial chylomicronemia syndrome related chronic pancreatitis: a single-center study," Hepatobiliary \& Pancreatic Diseases International, vol. 13, no. 2, pp. 209-214, 2014.

[20] M. Castiñeira-Alvariño, B. Lindkvist, M. Luaces-Regueira et al., "The role of high fat diet in the development of complications of chronic pancreatitis," Clinical Nutrition, vol. 32, no. 5, pp. 830836, 2013.

[21] H. D. L. Suero, E. C. V. Raya, M. T. S. Allende et al., "Autoimmune pancreatitis in Barcelona as assessed by the international consensus diagnostic criteria (ICDC). Review of a series of 25 patients from two centers," Pancreatology, vol. 13, no. 4, supplement 1, p. e17, 2013.

[22] C. Marra-López, A. Marcaide, P. R. de la Piscina et al., "Chronic pancreatitis study in Txagorritxu-Araba university hospital (Vitoria-Gasteiz, Alava, Basque-Country)," Pancreatology, vol. 13, no. 4, p. e15, 2013. 
[23] S. Vyas, J. Skipworth, F. Prete et al., "Splanchnic venous thrombosis in acute pancreatitis: is there a role for routine systemic anticoagulation in severe acute pancreatitis?" $H P B$, vol. 14, pp. 249-250, 2012.

[24] G. Sisman, Y. Erzin, and H. Senturk, "The effect of Helicobacter pylori infection on the development of splenic vein thrombosis in chronic pancreatitis patients," Gastroenterology, vol. 142, no. 2, supplement 1, p. S55, 2012.

[25] H. De León, H. Allende, X. Merino, J. Balsells, L. Guarner, and $\mathrm{X}$. Molero, "Autoimmune pancreatitis in Barcelona as assessed by the Honolulu diagnostic criteria. Review of a series of 16 patients," Pancreatology, vol. 12, no. 6, p. 565, 2012.

[26] S. Chooklin and O. Hranat, "Spleen lesions in acute pancreatitis," Pancreatology, vol. 9, no. 4, p. 494, 2009.

[27] T. Keck, G. Marjanovic, C. Fernandez-Del Castillo et al., "The inflammatory pancreatic head mass: significant differences in the anatomic pathology of German and American patients with chronic pancreatitis determine very different surgical strategies," Annals of Surgery, vol. 249, no. 1, pp. 105-110, 2009.

[28] F. Makowiec, H. Riediger, J. Emmrich, J. Kröger, U. T. Hopt, and U. Adam, "Prophylactic splenectomy for splenic vein thrombosis in patients undergoing resection for chronic pancreatitis," Zentralblatt für Chirurgie, vol. 129, no. 3, pp. 191-195, 2004.

[29] H. Malíková, M. Kašpar, J. Weichet, A. Sobotovičová, and J. Drechslerová, "Vascular complications of acute pancreatitis," Ceska Radiologie, vol. 56, no. 5, pp. 275-279, 2002.

[30] Y. Dörffel, U. Wruck, R. I. Rückert, P. Romaniuk, W. Dörffel, and W. Wermke, "Vascular complications in acute pancreatitis assessed by color duplex ultrasonography," Pancreas, vol. 21, no. 2, pp. 126-133, 2000.

[31] R. Arotcarena, L. Heyries, J. Moreau et al., "Natural history of non alcoholic and non familial chronic pancreatitis. Results of a multicentre study," Gastroenterologie Clinique et Biologique, vol. 23, no. 12, pp. 1368-1375, 1999.

[32] H. Friess, C. Dervenis, C. Avgerinos et al., "Vascular complications in chronic pancreatitis," Hellenic Journal of Gastroenterology, vol. 10, no. 3, pp. 220-224, 1997.

[33] W. Roesch, G. Lux, J. F. Riemann, and L. Hoh, "Chronic pancreatitis and surrounding organs," Fortschritte der Medizin, vol. 99, no. 29, pp. 1118-1121, 1981.

[34] J. R. Sibert, "Hereditary pancreatitis in England and Wales," Journal of Medical Genetics, vol. 15, no. 3, pp. 189-201, 1978.

[35] I. Nordback and T. Sisto, "Peripancreatic vascular occlusions as a complication of pancreatitis," International Surgery, vol. 74, no. 1, pp. 36-39, 1989.

[36] S. Shalimar, S. Midha, P. Bhardwaj, and P. K. Garg, "Long-term pain relief with optimized medical therapy including antioxidants in patients with chronic pancreatitis," Gastroenterology, no. 5, supplement 1, p. S-547, 2011.

[37] S. S. Vege, V. Pribramska, J. Trna, P. S. Kamath, and S. T. Chari, "Natural history of splanchnic venous thrombosis in acute pancreatitis: a population-based study," Pancreas, vol. 38, no. 8 , p. 1059, 2009.

[38] J. Easler, V. Muddana, A. Furlan et al., "Portosplenomesenteric venous thrombosis in patients with acute pancreatitis is associated with pancreatic necrosis and usually has a benign course," Clinical Gastroenterology and Hepatology, vol. 12, no. 5, pp. 854862, 2014.

[39] V. Muddana, J. J. Easler, A. Slivka, D. C. Whitcomb, G. I. Papachristou, and D. Yadav, "Prevalence, risk factors and management of peripancreatic venous thrombosis (PPVT) in acute pancreatitis (AP)," Gastroenterology, vol. 142, no. 5, supplement 1, p. S320, 2012.

[40] K. J. Mortelé, P. J. Mergo, H. M. Taylor et al., "Peripancreatic vascular abnormalities complicating acute pancreatitis: contrastenhanced helical CT findings," European Journal of Radiology, vol. 52, no. 1, pp. 67-72, 2004.

[41] F. H. B. Pimentel, C. I. Añez De Gómez, A. R. S. Folena, R. C. M. Silva, A. Vieira, and E. G. Rolim, "Chronic pancreatitis complications in patients seen at the outpatient clinic," Gastrenterologia Endoscopia Digestiva, vol. 22, no. 6, pp. 231-234, 2003.

[42] K. J. Mortelé, P. J. Mergo, H. M. Taylor, M. D. Ernst, and P. R. Ros, "Splenic and perisplenic involvement in acute pancreatitis: determination of prevalence and morphologic helical CT features," Journal of Computer Assisted Tomography, vol. 25, no. 1, pp. 50-54, 2001.

[43] G. H. Sakorafas, M. G. Sarr, D. R. Farley, and M. B. Farnell, "The significance of sinistral portal hypertension complicating chronic pancreatitis," American Journal of Surgery, vol. 179, no. 2, pp. 129-133, 2000.

[44] C. Rogers and E. C. Klatt, "Splenic vein thrombosis in patients with acute pancreatitis," International Journal of Pancreatology, vol. 5, no. 2, pp. 117-121, 1989.

[45] B. O. Hofer, J. A. Ryan Jr., and P. C. Freeny, "Surgical significance of vascular changes in chronic pancreatitis," Surgery Gynecology and Obstetrics, vol. 164, no. 6, pp. 499-505, 1987.

[46] R. McElroy and P. A. Christiansen, "Hereditary pancreatitis in a kinship associated with portal vein thrombosis," The American Journal of Medicine, vol. 52, no. 2, pp. 228-241, 1972.

[47] R. Talukdar, A. Bhattacharrya, B. Rao, M. Sharma, and D. N. Reddy, "Clinical utility of the Revised Atlanta Classification of acute pancreatitis in a prospective cohort: have all loose ends been tied?" Pancreatology, vol. 14, no. 4, pp. 257-262, 2014.

[48] K. Jakchairoongruang and K. Arjhansiri, "Prognostic value of contrast-enhanced computed tomography in acute pancreatitis," Asian Biomedicine, vol. 7, no. 3, pp. 357-364, 2013.

[49] T. Ishikawa, A. Itoh, H. Kawashima et al., "Peripancreatic vascular involvements of autoimmune pancreatitis," Journal of Gastroenterology and Hepatology, vol. 27, no. 12, pp. 1790-1795, 2012.

[50] S. D. Chowdhury, J. Augustine, and A. Chacko, "Chronic pancreatitis amongst children in India," Pancreatology, vol. 11, p. 35, 2011.

[51] A. K. Agarwal, R. Kumar K., S. Agarwal, and S. Singh, "Significance of splenic vein thrombosis in chronic pancreatitis," American Journal of Surgery, vol. 196, no. 2, pp. 149-154, 2008.

[52] Y. Tsushima, T. Tamura, K. Tomioka, C. Okada, S. Kusano, and K. Endo, "Transient splenomegaly in acute pancreatitis," British Journal of Radiology, vol. 72, pp. 637-643, 1999.

[53] C.-C. Lin, H.-P. Wang, M.-F. Chen et al., "Chronic calcifying pancreatitis in Taiwan: a multicentric study and comparison with western countries," Hepato-Gastroenterology, vol. 44, no. 15, pp. 842-848, 1997.

[54] M. Takase, K. Suda, F. Suzuki, T. Nakamura, and S. Futagawa, "A histopathologic study of localized portal hypertension as a consequence of chronic pancreatitis," Archives of Pathology \& Laboratory Medicine, vol. 121, no. 6, pp. 612-614, 1997.

[55] D. Keeling, T. Baglin, C. Tait et al., "Guidelines on oral anticoagulation with warfarin-fourth edition," British Journal of Haematology, vol. 154, no. 3, pp. 311-324, 2011. 
[56] S. M. Weber and L. F. Rikkers, "Splenic vein thrombosis and gastrointestinal bleeding in chronic pancreatitis," World Journal of Surgery, vol. 27, no. 11, pp. 1271-1274, 2003.

[57] T. R. Heider, S. Azeem, J. A. Galanko et al., "The natural history of pancreatitis-induced splenic vein thrombosis," Annals of Surgery, vol. 239, no. 6, pp. 876-882, 2004.

[58] J. R. Butler, G. J. Eckert, N. J. Zyromski, M. J. Leonardi, K. D. Lillemoe, and T. J. Howard, "Natural history of pancreatitisinduced splenic vein thrombosis: a systematic review and metaanalysis of its incidence and rate of gastrointestinal bleeding," $H P B$, vol. 13, no. 12, pp. 839-845, 2011. 


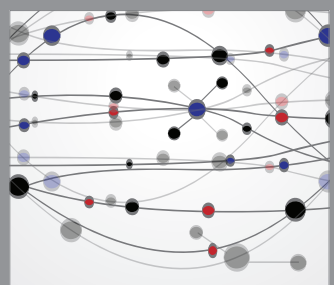

The Scientific World Journal
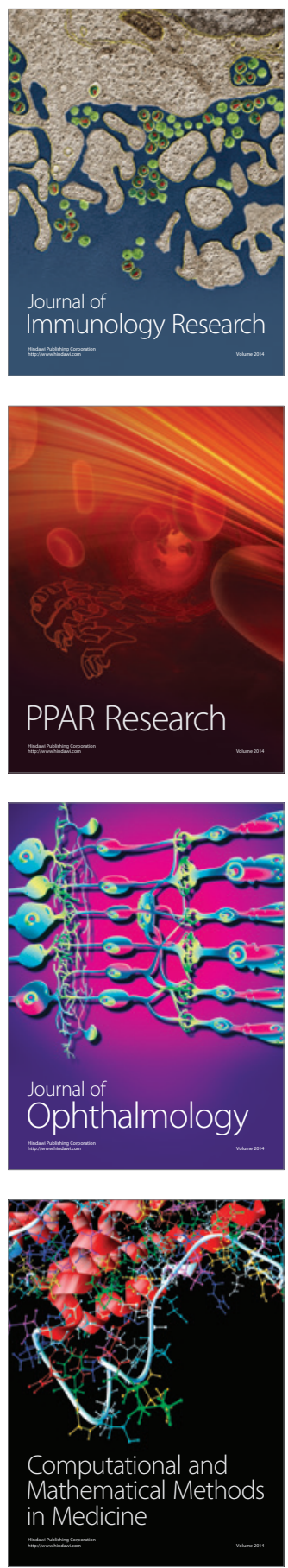

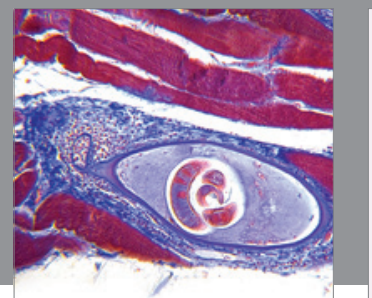

Gastroenterology

Research and Practice
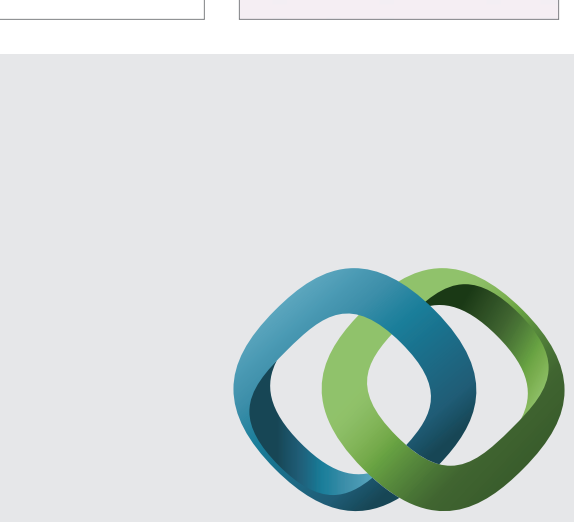

\section{Hindawi}

Submit your manuscripts at

http://www.hindawi.com
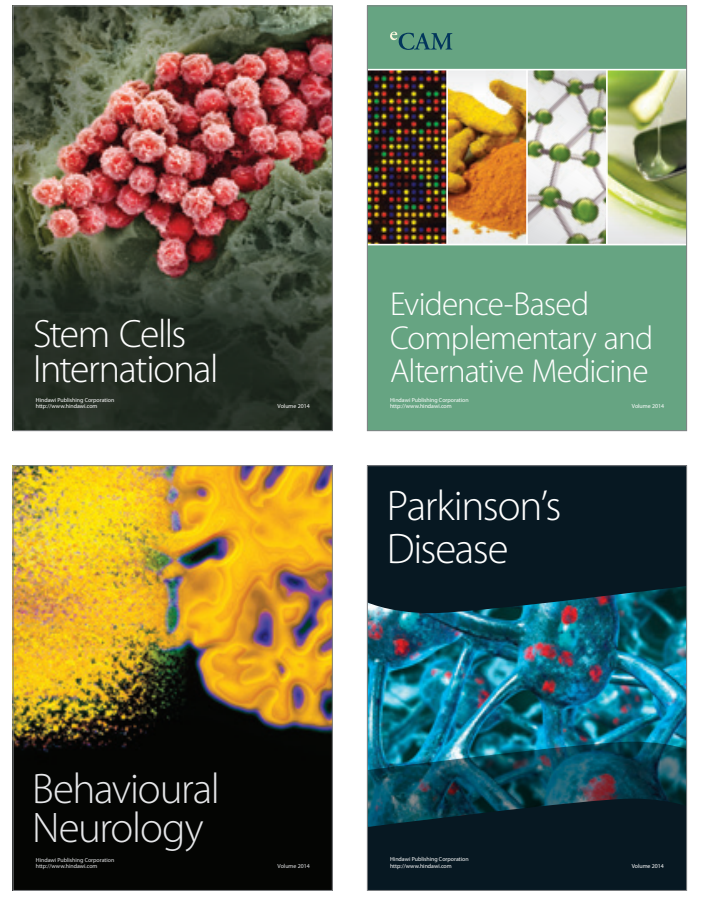
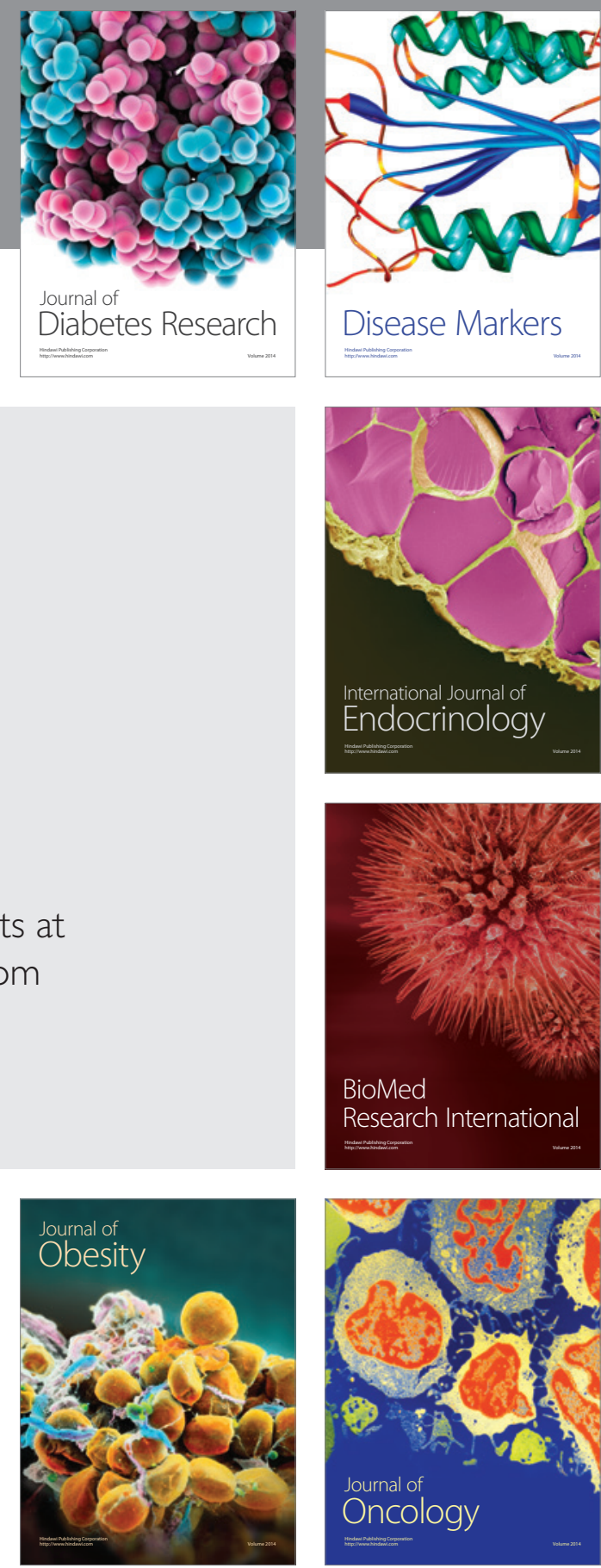

Disease Markers
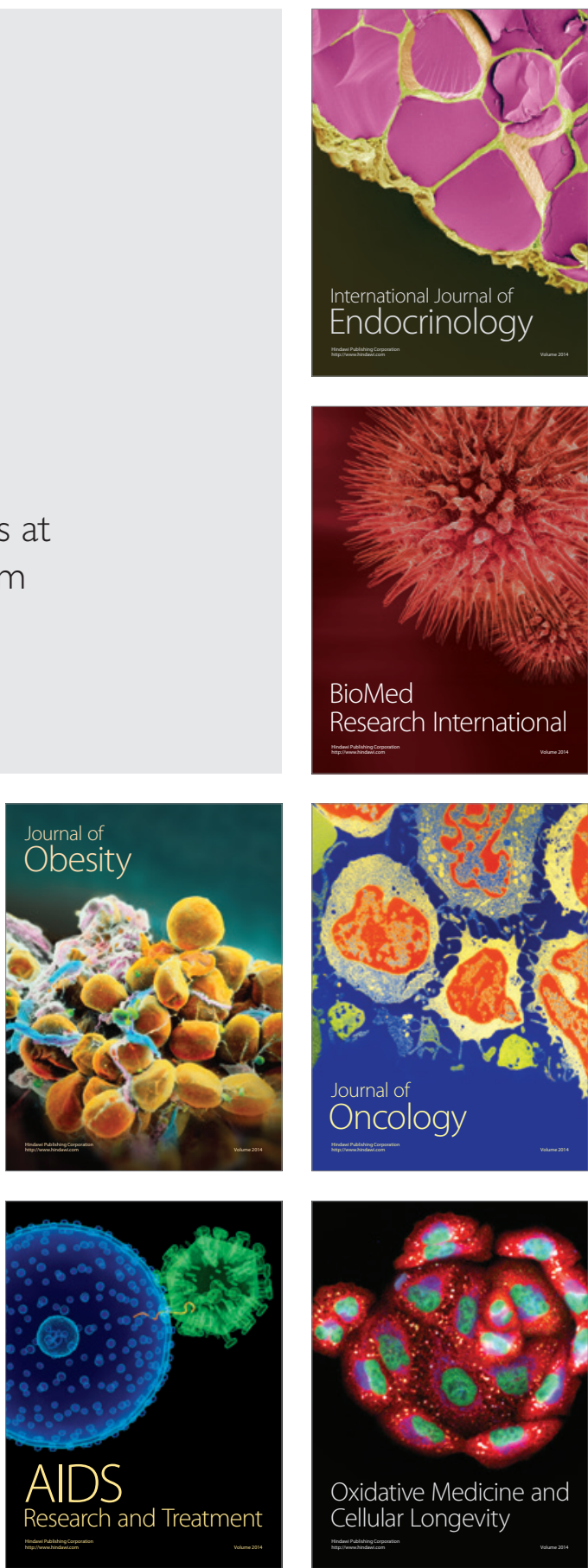